NBER WORKING PAPER SERIES

\title{
MICRO EFFECTS OF MACRO ANNOUNCEMENTS: REAL-TIME PRICE DISCOVERY IN FOREIGN EXCHANGE
}

\author{
Torben G. Andersen \\ Tim Bollerslev \\ Francis X. Diebold \\ Clara Vega \\ Working Paper 8959 \\ http://www.nber.org/papers/w8959
NATIONAL BUREAU OF ECONOMIC RESEARCH 1050 Massachusetts Avenue
Cambridge, MA 02138
May 2002

This work was supported by the National Science Foundation and the Wharton Financial Institutions Center. We are grateful to Olsen and Associates for making available their real-time exchange rate quotations data, and to Money Market Services International for making available their news announcement expectations data. For useful comments we thank the Editor and three referees, as well as Ricardo Cabellero, Dean Croushore, Kathryn Dominguez, Bernard Dumas, Martin Evans, Michael Fleming, Jeff Frankel, Linda Goldberg, Ken Kavajecz, Rich Lyons, Nelson Mark, Frank Schorfheide, Nick Souleles, Allan Timmermann, Mark Watson, Ingrid Werner, and Jonathan Wright, and participants at the CAF Conference in Denmark on Market Microstructure and High-Frequency Data in Finance, the University of Wisconsin Conference on Empirical Models of Exchange Rates, the Federal Reserve Bank of Philadelphia Conference on Real-Time Data Analysis, the NBER International Finance and Macroeconomics Program Meeting, and seminars at the University of Pennsylvania and the University of Houston. The views expressed herein are those of the authors and not necessarily those of the National Bureau of Economic Research.

(C) 2002 by Torben G. Andersen, Tim Bollerslev, Francis X. Diebold and Clara Vega. All rights reserved. Short sections of text, not to exceed two paragraphs, may be quoted without explicit permission provided that full credit, including (C) notice, is given to the source. 
Micro Effects of Macro Announcements:

Real-Time Price Discovery in Foreign Exchange

Torben G. Andersen, Tim Bollerslev, Francis X. Diebold and Clara Vega

NBER Working Paper No. 8959

May 2002

JEL No. F3, G1

\begin{abstract}
Using a new dataset consisting of six years of real-time exchange rate quotations, macroeconomic expectations, and macroeconomic realizations (announcements), we characterize the conditional means of U.S. dollar spot exchange rates versus German Mark, British Pound, Japanese Yen, Swiss Franc, and the Euro. In particular, we find that announcement surprises (that is, divergences between expectations and realizations, or "news") produce conditional mean jumps; hence high-frequency exchange rate dynamics are linked to fundamentals. The details of the linkage are intriguing and include announcement timing and sign effects. The sign effect refers to the fact that the market reacts to news in an asymmetric fashion: bad news has greater impact than good news, which we relate to recent theoretical work on information processing and price discovery.
\end{abstract}

Torben G. Andersen

Department of Finance

Kellogg School

Northwestern University

and NBER

t-andersen@kellogg.nwu.edu

Francis X. Diebold

Departments of Economics, Finance and Statistics

University of Pennsylvania

and NBER

fdiebold@sas.upenn.edu
Tim Bollerslev

Departments of Economics and Finance

Duke University

and NBER

boller@econ.duke.edu

Clara Vega

Graduate Group in Economics

University of Pennsylvania

cvega@ssc.upenn.edu 


\section{Introduction}

How is news about fundamentals incorporated into asset prices? The topic confronted by this question - characterization of the price discovery process - is of basic importance to all of financial economics. Unfortunately, it is also one of the least well understood issues. Indeed, some influential empirical studies have gone so far as to suggest that for some assets - notably foreign exchange - prices and fundamentals are largely disconnected. ${ }^{1}$

In this paper we provide an empirical examination of price discovery in the challenging context of foreign exchange. Using a newly-constructed dataset consisting of six years of real-time exchange rate quotations, macroeconomic expectations, and macroeconomic realizations (announcements), we characterize the conditional means of U.S. dollar spot exchange rates for German Mark, British Pound, Japanese Yen, Swiss Franc and the Euro. In particular, we show that announcement surprises (that is, the difference between expectations and realizations, or "news") produce conditional mean jumps, and we provide a detailed analysis of the speed and pattern of adjustment.

We show that conditional mean adjustments of exchange rates to news occur quickly, effectively amounting to "jumps," in contrast to conditional variance adjustments, which are much more gradual, and that an announcement's impact depends on its timing relative to other related announcements, and on whether the announcement time is known in advance. We find, moreover, that the adjustment response pattern is characterized by a sign effect: bad news has greater impact than good news. Finally, we relate our results to recent theoretical and empirical work on asset return volatility and its association with information processing and price discovery.

The paper relates to earlier work in intriguing ways, but at least three features differentiate our findings from previous results along important dimensions. These include our focus on foreign exchange markets, our focus on conditional mean as opposed to conditional variance dynamics, and the length and breadth of our sample of exchange rate and announcement data. Let us discuss them briefly in turn.

First, we focus on foreign exchange markets as opposed to stock or bond markets, and we address the central open issue in exchange rate economics - the link between exchange rates and fundamentals. It is comforting, however, that a number of recent papers focusing largely on bond markets reach conclusions similar to ours. Balduzzi, Elton and Green (2001), for example, examine the effects of economic news on prices in the U.S. inter-dealer government bond market, finding strong news effects

\footnotetext{
${ }^{1}$ The classic statement is of course Meese and Rogoff (1983). For a good survey of the subsequent empirical exchange rate literature through the early 1990s, see Frankel and Rose (1995). In later work, Mark (1995) and Mark and Sul (1998) find that fundamentals matter in the long run but not in the short run. Evans and Lyons (2002) find that order flow matters in the short run but fail to link order flow to fundamentals.
} 
and quick incorporation of news into bond prices, while Fleming and Remolona $(1997,1999)$ show that the largest bond price movements stem from the arrival of news announcements. ${ }^{2}$

Second, we focus primarily on exchange rate conditional means as opposed to conditional variances. That is, we focus primarily on the determination of exchange rates themselves, as opposed to their volatility. We maintain this focus both because the conditional mean is of intrinsic interest, and because high-frequency discrete-time volatility cannot be extracted accurately unless the conditional mean is modeled adequately. Hence our work differs in important respects from that of Andersen and Bollerslev (1998), Bollerslev, Cai and Song (2000), Ederington and Lee (1993), and Payne (1996), for example, who examine calendar and news effects in high-frequency asset return volatility but do not consider the effects of news on returns themselves.

Third, we use a new dataset which span a comparatively long time period, and include a broad set of exchange rates and macroeconomic indicators.

Notwithstanding the improvements obtained through the above consideration, our results are quite consistent with prior related work. Indeed, several studies have linked macroeconomic news announcements to jumps in exchange rates, and our findings may be viewed as providing confirmation and elaboration. Goodhart, Hall, Henry, and Pesaran (1993), for example, examine one year of highfrequency Dollar/Pound exchange rates and two specific news events - a U.S. trade figure announcement and a U.K. interest rate change - and conclude in each case that the news caused an exchange rate jump. Similarly, Almeida, Goodhart and Payne (1998) in their study of three years of high-frequency $\mathrm{DM} /$ Dollar exchange rates and a larger set of news announcements, document systematic short-lived news effects. Finally, Dominguez (1999) argues that most large exchange rate changes occur within 10 seconds of a macroeconomic news announcement, and that close timing of central bank interventions to news announcements increases their effectiveness.

We proceed as follows. In section 2 we describe our high-frequency exchange rate and macroeconomic expectations and announcements data. In section 3 we characterize the speed and pattern of exchange rate adjustment to macroeconomic news, and we document, among other things, the sign effects (i.e., a larger exchange rate response to bad than good news). In section 4 we relate the sign effects to recent theories of information processing and price discovery. We conclude in section 5 .

\section{Real-Time Exchange Rates, Expected Fundamentals, and Announced Fundamentals}

\footnotetext{
${ }^{2}$ Also, in concurrent related work for T-bond futures, Hautsch and Hess (2001) report highly significant, but shortlived, price and volatility impacts in response to new and revised employment figures.
} 
Throughout the paper we use data on exchange rate returns in conjunction with data on expectations and announcements of macroeconomic fundamentals. The data are novel in several respects, such as the simultaneous high frequency and long calendar span of the exchange rate returns, as well as the real-time nature of the expectations and announcements of fundamentals. Here we describe them in some detail.

\section{Exchange Rate Data}

The raw 5-minute $\mathrm{CHF} / \$, \mathrm{DM} / \$$, Euro $/ \$$, Pound $/ \$$ and $\mathrm{Yen} / \$$ return series were obtained from Olsen and Associates. The full sample consists of continuously-recorded 5-minute returns from January 3, 1992 through December 30, 1998, or 2,189 days, for a total of 2,189.288 $=630,432$ high-frequency foreign exchange (FX) return observations. As in Müller et al. (1990) and Dacorogna et al. (1993), we use all of the interbank quotes that appeared on the Reuters screen during the sample period to construct our 5-minute returns. Each quote consists of a bid and an ask price together with a "time stamp" to the nearest second. After filtering the data for outliers and other anomalies, we obtain the average log price at each 5-minute mark by linearly interpolating the average of the log bid and the log ask at the two closest ticks. We then construct continuously-compounded returns as the change in these 5-minute average log bid and ask prices. Goodhart, Ito and Payne (1996) and Danielsson and Payne (1999) find that the basic characteristics of 5-minute FX returns constructed from quotes closely match those calculated from transactions prices (which are not generally available for the foreign exchange market).

It is well known that the activity in the foreign exchange market slows decidedly during weekends and certain holiday non-trading periods; see Müller et al. (1990). Hence, as is standard in the literature, we explicitly excluded a number of days from the raw 5-minute return series. Whenever we did so, we always cut from 21:05 GMT the night before to 21:00 GMT that evening. This particular definition of a "day" was motivated by the ebb and flow in the daily FX activity patterns documented in Bollerslev and Domowitz (1993) and keeps the daily periodicity intact. In addition to the thin weekend trading period from Friday 21:05 GMT until Sunday 21:00 GMT, we removed several fixed holidays, including Christmas (December 24 - 26), New Year's (December 31 - January 2), and July Fourth. We also cut the moving holidays of Good Friday, Easter Monday, Memorial Day, July Fourth (when it falls officially on July 3), and Labor Day, as well as Thanksgiving and the day after. Although our cuts do not account for all of the holiday market slowdowns, they capture the most important daily calendar effects.

Finally, we deleted some of the returns contaminated by brief lapses in the Reuters data feed. This problem, which occurs almost exclusively during the earliest part of the sample, manifests itself as sequences of zero or constant 5-minute returns in places where missing quotes had been interpolated. To 
remedy this, we simply removed from each exchange rate series the days containing the fifteen longest zero and constant runs. Because of the overlap among sets of days defined by this criterion, we actually removed only 25 days.

In the end we are left with 1,724 days of data, containing $T=1,724 \cdot 288=496,512$ highfrequency 5-minute return observations. Standard descriptive statistics reveal that the 5-minute returns have means that are negligible and dwarfed by the standard deviations, and that they are approximately symmetric but distinctly non-Gaussian, due to excess kurtosis. Ljung-Box statistics indicate serial correlation in both returns and absolute returns.

To assess the economic relevance of the temporal dependencies in the return series, we turn to the autocorrelations in column one of Figure 1. The raw returns display tiny, but nevertheless statistically significant, serial correlation at the very shortest lags, presumably due to microstructure effects. However, the short-lag return serial correlation is negligible relative to the strong serial correlation in absolute returns, shown in column two of Figure 1. The sample autocorrelations of absolute returns display very slow decay and pronounced diurnal variation, in line with the results of Dacorogna et al. (1993) and Andersen and Bollerslev (1998). Interestingly, not only the shapes but also the amplitudes of the diurnal patterns in absolute return autocorrelations differ noticeably across currencies.

\section{Expected Fundamentals, Announced Fundamentals, and News}

We use the International Money Market Services (MMS) real-time data on expected and realized ("announced") macroeconomic fundamentals, defining "news" as the difference between expectations and realizations. Every week since 1977, MMS has conducted a Friday telephone survey of about forty money managers, collected forecasts of all indicators to be released during the next week, and reported the median forecasts from the survey. Numerous influential studies, from early work such as Urich and Wachtel (1984) through recent work such as Balduzzi, Elton and Green (2001), have verified that the MMS expectations contain valuable information about the forecasted variable, and in most cases are unbiased and less variable than those produced from extrapolative benchmarks such as ARMA models.

Table 1 provides a brief description of salient aspects of U.S. and German economic news announcements. We show the total number of observations in our news sample, the agency reporting each announcement, and the time of the announcement release. Note that U.S. announcements times are known in advance, whereas only the day for the German announcements are known in advance but their timing within the day is variable and unknown a priori.

The target Fed funds rate deserves special mention. The Federal Open Market Committee's (FOMC) announcement of the federal funds rate target, although likely producing important news, is 
nonstandard and hence is not typically examined. It is nonstandard because prior to February 1994 it was not announced; instead, the FOMC signaled the target rate, but did not state it explicitly, through open market operations performed from 11:30 to 11:35 am Eastern time on the day of the FOMC meeting. In February 1994, the FOMC began to announce changes in the target rate on meeting days, albeit at irregular times, and from 1995 onward it announced the target rate on meeting days regularly at 2:15 pm Eastern time, as described in Kuttner (2001).

To assess the effects of FOMC news, we need to know announcement days and times, as well as the market's expected Fed funds rate target and the announced (or signaled) value. Determination of announcement days and times is relatively straightforward. We collected the irregular 1994 announcement times from Reuters. ${ }^{3}$ Before 1994 we use an 11:30 am Eastern announcement time, and after March,1995 we use a 2:15 pm announcement time. ${ }^{4}$ Determination of market expectations is similarly straightforward: we use MMS survey data on expected federal fund rate targets from January 1992 to December 1998..$^{5}$ The announcements themselves are trickier to construct, due to the pre-1994 FOMC secrecy; we use the announcement data constructed by Brandt, Edelen and Kavajecz (2001), kindly provided by Kenneth Kavajecz.

In Table 2 we show the pattern of U.S. release dates throughout the month. ${ }^{6}$ This is of potential importance, because there is some redundancy across indicators. For example, consumer and producer price indexes, although of course not the same, are nevertheless related, and Table 2 reveals that the producer price index is released earlier in the month. Hence one might conjecture that producer price news would explain more exchange rate return variation than consumer price news, as the typical amount of consumer price news revealed may be relatively small given the producer price news revealed earlier in the month.

\footnotetext{
${ }^{3}$ The announcement times were 11:05 am Eastern time on 02/04/94, 2:20 pm on 03/22/94 and 07/06/94, 2:30 pm on $11 / 15 / 94,2: 26 \mathrm{pm}$ on $05 / 17 / 94,2: 23 \mathrm{pm}$ on $12 / 20 / 94,1: 17 \mathrm{pm}$ on $08 / 16 / 94,2: 22 \mathrm{pm}$ on $09 / 27 / 94,2: 24 \mathrm{pm}$ on $02 / 01 / 95$.

${ }^{4}$ The FOMC can also surprise the market by changing the Fed funds target between FOMC meetings. Because this does not happen often in our sample (5 out of 62 times) and we do not have the exact timing of such policy changes, we do not account for them. Similarly, data limitations prevent us from investigating the effect of Fed open market operations; see Harvey and Huang (2002) for a recent analysis involving the earlier 1982-88 time period.
}

${ }^{5}$ One could also attempt to infer expectations from Fed funds futures prices, as in Rudebusch (1998) and Kuttner (2001).

${ }^{6}$ The design of the table follows Chart 2 of Fleming and Remolona (1997). 
Because units of measurement differ across economic variables, we follow Balduzzi, Elton and Green (2001) in using standardized news. That is, we divide the surprise by its sample standard deviation to facilitate interpretation. The standardized news associated with indicator $k$ at time $t$ is

$$
S_{k t}=\frac{A_{k t}-E_{k t}}{\hat{\sigma}_{k}}
$$

where $A_{k t}$ is the announced value of indicator $k, E_{k t}$ is the market expected value of indicator $k$ as distilled in the MMS median forecast, and $\hat{\sigma}_{k}$ is the sample standard deviation of $A_{k t}-E_{k t}$. Use of standardized news facilitates meaningful comparisons of responses of different exchange rates to different pieces of news. Operationally, we estimate the responses by regressing asset returns on news; because $\hat{\sigma}_{k}$ is constant for any indicator $k$, the standardization affects neither the statistical significance of response estimates nor the fit of the regressions.

Before proceeding, we pause to discuss in greater detail the possibility that the MMS forecasts may not capture all information available immediately before the announcement. Surely information does not stop flowing between the time that the MMS forecast is produced and the time that the macroeconomic indicator is realized; hence the MMS forecasts may be "stale." Just how stale they are, however, is an empirical matter. This issue has been investigated already in the context of news effects on interest rates by Balduzzi, Elton and Green (1998), who regress the actual announcement, $A_{i}$, on the median forecast of the MMS survey, $F_{i}$, and the change in the (very announcement sensitive) ten-year note yield from the time of the survey to the time of the announcement, $\Delta y$ :

$$
A_{i t}=\alpha_{0 i}+\alpha_{1 i} F_{i t}+\alpha_{2 i} \Delta y_{t}+e_{i t}
$$

This particular regression facilitates the testing of several hypotheses. First, if there is information content in the MMS survey data, the coefficient estimates $\alpha_{1 i}$ should be positive and significant. Second, if the survey information is unbiased, the $\alpha_{0 i}$ coefficient estimates should be insignificant, and the slope terms $\alpha_{1 i}$ should be insignificantly different from unity. Finally, if expectations are revised between the survey and the announcement, there should be a reaction in the bond price at the time of the forecast revision, and we should see a relationship between the change in yield and the announcement. As already mentioned, Balduzzi, Elton and Green (2001) find, as have many others, that most of the MMS forecasts 
contain information and are unbiased. ${ }^{7}$ More importantly for the issue at hand, however, they also find that for most indicators the hypothesis that $\alpha_{2 i}=0$ cannot be rejected, indicating that the MMS forecasts do not appear significantly stale.

\section{Exchange Rates and Fundamentals}

We will specify and estimate a model of high-frequency exchange rate dynamics that allows for the possibility of news affecting both the conditional mean and the conditional variance. Our goal is to determine whether high-frequency exchange rate movements are linked to fundamentals, and if so how. Our motivations are twofold. The first motivation is obviously the possibility of refining our understanding of the fundamental determinants of exchange rates, the central and still largely-unresolved question of exchange rate economics. The second motivation is the possibility of improved highfrequency volatility estimation via allowance for jumps due to news, as misspecification of the conditional mean (for example by failing to allow for jumps, if jumps are in fact present) will produce distorted volatility estimates in discrete time. ${ }^{8}$

\section{Modeling the Response of Exchange Rates to News}

We model the 5-minute spot exchange rate, $R_{t}$, as a linear function of $I$ lagged values of itself, and $J$ lags of news on each of $K$ fundamentals:

$$
R_{t}=\beta_{0}+\sum_{i=1}^{I} \beta_{i} R_{t-i}+\sum_{k=1}^{K} \sum_{j=0}^{J} \beta_{k j} S_{k, t-j}+\varepsilon_{t}, \quad t=1, \ldots, T .
$$

As discussed earlier, $K=41$ and $T=496,512$. We chose $I=5$ and $J=2$ based on the Schwarz and Akaike information criteria. ${ }^{9}$

\footnotetext{
${ }^{7}$ In addition to being unbiased, Pearce and Roley (1985) and McQueen and Roley (1993) also find that the MMS surveys are more accurate, in the sense of having lower mean squared errors, than the forecasts from standard autoregressive time series models.

${ }^{8}$ In this paper, we are primarily interested in exchange rate volatility only insofar as it is relevant for inference regarding exchange rate conditional mean dynamics. We have reserved for future work a detailed analysis of volatility in relation to conditional mean and variance jumps. For a preliminary discussion of the effects on realized volatility of conditional mean and variance jumps, see Andersen, Bollerslev, Diebold and Labys (2001b).

${ }^{9}$ We also tried allowing for negative $J$, to account for announcement leakage before the official time, and more generally to account for the fact that the MMS forecasts might not capture all information available immediately before the announcement, but doing so proved unnecessary. This accords with the earlier-discussed finding of Balduzzi, Elton and Green (2001) that, to a good approximation, the MMS forecasts do capture all information available immediately before the announcement. Moreover, if leakage is present (and introspection, if not the
} 
We allow the disturbance term in the 5-minute return model (1) to be heteroskedastic. Following Andersen and Bollerslev (1998), we estimate the model using a two-step weighted least squares (WLS) procedure. We first estimate the conditional mean model (1) by ordinary least squares regression, and then we estimate the time-varying volatility of $\varepsilon_{t}$ from the regression residuals, which we use to perform a weighted least squares estimation of (1). We approximate the disturbance volatility using the model:

$$
\left|\hat{\varepsilon}_{t}\right|=c+\psi \frac{\hat{\sigma}_{d(t)}}{\sqrt{288}}+\sum_{k=1}^{K} \sum_{j^{\prime}=0}^{J^{\prime}} \beta_{k j^{\prime}}\left|S_{k, t-j^{\prime}}\right|+\left(\sum_{q=1}^{Q}\left(\delta_{q} \cos \left(\frac{q 2 \pi t}{288}\right)+\varphi_{q} \sin \left(\frac{q 2 \pi t}{288}\right)\right)+\sum_{r=1}^{R} \sum_{j^{\prime \prime}=0}^{J^{\prime \prime}} \gamma_{r j^{\prime \prime}} D_{r, t-j^{\prime \prime}}\right)+u_{t} .
$$

The left-hand-side variable, $\left|\hat{\varepsilon}_{t}\right|$, is the absolute value of the residual of equation (1), which proxies for the volatility in the 5-minute interval $t$. As revealed by the right-hand side of equation (2), we model 5minute volatility as driven partly by the volatility over the day containing the 5-minute interval in question, $\hat{\sigma}_{d(t)}$, partly by news $S_{k, t}$, and partly by a calendar effect pattern consisting largely of intraday effects that capture the high-frequency rhythm of deviations of intraday volatility from the daily average. Specifically, we split the calendar effects into two parts. The first is a Fourier flexible form with trigonometric terms that obey a strict periodicity of one day. ${ }^{10}$ The second is a set of dummy variables $D_{r, t}$ capturing the Japanese lunch, the Japanese open, and the U.S. late afternoon during U.S. daylight saving time.

Let us explain in greater detail. Consider first the daily volatility, $\hat{\sigma}_{d(t)}$, which is the one-dayahead volatility forecast for day $d(t)$ (the day that contains time $t$ ) from a simple daily conditionallyGaussian GARCH(1,1) model using spot exchange rate returns from January 2, 1986 through December 31,1998 . Because $\hat{\sigma}_{d(t)}$ is intended to capture the "average" level of volatility on day $d(t)$, it makes sense to construct it using a $\operatorname{GARCH}(1,1)$ model, which is routinely found to provide accurate approximations to daily asset return volatility dynamics. ${ }^{11}$

empirics, suggests that there is likely some leakage, however small) then our estimated news response coefficients, which correspond only to the impact at the time of the official announcement, are lower bounds for the total news impact.

${ }^{10} \mathrm{We}$ also translate the Fourier terms leftward as appropriate during U.S. daylight savings time. (Only North America and Europe have daylight savings time.)

${ }^{11}$ For surveys of GARCH modeling in financial environments, see Bollerslev, Chou and Kroner (1992) and Diebold and Lopez (1995). Other possibilities, also explored with little change in qualitative results, include use of daily realized volatilities as in Andersen, Bollerslev, Diebold and Labys (2001a, b) and Andersen, Bollerslev, Diebold and Ebens (2001). 
Now consider the Fourier part for the calendar effects. This is a very flexible functional form that may be given a semi-nonparametric interpretation (Gallant, 1981). The Schwarz and Akaike information criteria chose a rather low $Q=4$ for all currencies, which achieves parametric economy and promotes smoothness in the intraday seasonal pattern.

Finally, consider the news effects $S$ and non-Fourier calendar effects $D$. To promote tractability while simultaneously maintaining flexibility, we impose polynomial structure on the response patterns associated with the $\beta_{k j^{\prime}}$ and $\gamma_{r j^{\prime \prime}}$ parameters. ${ }^{12}$ For example, if a particular news surprise affects volatility from time $t_{0}$ to time $t_{0}+J^{\prime}$, we can represent the impact over the event window $\tau=0,1 \ldots, J^{\prime}$ by a polynomial specification, $p(\tau)=c_{0}+c_{1} \tau+\ldots+c_{P} \tau^{P}$. For $P=J^{\prime}$ this would imply the estimation of $J^{\prime}+1$ polynomial coefficients and would not constrain the response pattern in any way. Use of a lowerordered polynomial, however, constrains the response in helpful ways: it promotes parsimony and hence tractability, retains flexibility of approximation, and facilitates the imposition of sensible constraints on the response pattern. For example, we can enforce the requirement that the impact effect slowly fades to zero by imposing $p\left(J^{\prime}\right)=0$.

Polynomial specifications ensure that the response patterns are completely determined by the response horizon $J^{\prime}$, the polynomial order $P$, and the endpoint constraint imposed on $p\left(J^{\prime}\right)$. For news effects $S$, we take $J^{\prime}=12, P=3$, and $p\left(J^{\prime}\right)=0 \cdot{ }^{13}$ The last condition leads to a polynomial with one less parameter; substituting $\tau=12$ into $p(\tau)$ we have, $p(\tau)=c_{0}\left[1-(\tau / 12)^{3}\right]+c_{1} \tau\left[1-(\tau / 12)^{2}\right]+c_{2} \tau^{2}[1-(\tau / 12)]$. We estimate each polynomial separately for all announcements and for each exchange rate. For example, payroll employment polynomial parameter estimates are $\left(\hat{c}_{0}, \hat{c}_{1}, \hat{c}_{2}\right)=(0.177175,-0.0645,0.008367)$ for the $\mathrm{DM} / \$,(0.163146,-0.05544,0.00704)$ for the $\mathrm{CHF} / \$,(0.114488,-0.03795,0.00477)$ for the Pound $/ \$$, $(0.108867,-0.03186,0.004003)$ for the Euro/\$, and $(0.11717,-0.04619,0.006289)$ for the Yen $/ \$$. Finally, $\beta_{k j^{\prime}}=\gamma_{k} p_{k}\left(j^{\prime}\right)$, where $\gamma_{k}$ is the coefficient estimate in equation (2). As for the non-Fourier calendar effect response patterns $D$, for the Japanese market opening we use $J^{\prime \prime}=6, P=1, p\left(J^{\prime \prime}\right)=0$, for

\footnotetext{
${ }^{12}$ This is particularly important in the case of conditional variance as opposed to conditional mean dynamics, because conditional variances turn out to adjust to shocks more slowly than do conditional means, thereby involving longer distributed lags, as we will subsequently emphasize. Hence, although tractability did not require the imposition of polynomial shape on the conditional mean distributed lags, it greatly enhances the accuracy of the conditional variance estimates.

${ }^{13}$ The "constraint" that volatility news effects linger for at most an hour $\left(J^{\prime}=12\right)$ is nonbinding. Initial experimentation allowing for $J^{\prime}=36$ revealed that one hour was enough for full adjustment, for all indicators and currencies.
} 
the Japanese lunch hour we use $J^{\prime \prime}=0$ (i.e., a standard dummy variable with no polynomial response), and for the U.S. late afternoon during U.S. daylight saving time we use $J^{\prime \prime}=60, P=2$, and $p(0)=p\left(J^{\prime \prime}\right)=0 . \cdot^{14}$ In closing this subsection, we note that we could have handled the volatility dynamics differently. In particular, instead of estimating explicit parametric models of volatility dynamics, we could have simply estimated equation (1) using heteroskedasticity and serial correlation consistent (HAC) standard errors. We find that approach less attractive than the one we adopted, for at least three reasons. First, we are interested not only in performing heteroskedasticity-robust inference about the coefficients (done both by our WLS and by HAC estimation) in equation (1), but also in obtaining the most efficient estimates of those coefficients. Second, although HAC estimation is asymptotically robust to residual heteroskedasticity of unknown form, its general robustness may come at the price of inferior finite-sample performance relative to the estimation of a well-specified parametric volatility model ${ }^{15}$ Third, despite the fact that they are not central to the analysis in the present paper, both the intra- and inter-day volatility patterns are of intrinsic financial economic interest and hence one may want estimates of these in other situations. Notwithstanding all of these $a$ priori arguments against the use of HAC estimation in the present context, as a check on the robustness of our results, we also performed all of the empirical work related to the mean effects using HAC estimation, with no change in any of the qualitative results (although a number of the coefficients were no longer statistically significant).

\section{News Effects I: News Announcements Matter, and Quickly}

The model (1)-(2) provides an accurate approximation to both conditional mean and conditional variance dynamics. Since the model contains so many variables and their lags, it would prove counterproductive to simply report all of the parameter estimates. Instead, Figure 2 shows the actual and fitted average intraday volatility patterns, which obviously agree fairly closely. Further, in Figure 3 we present graphically the results for the most important indicators, and we discuss those results (and some others, not shown in the figure) in what follows.

Let us first consider the effects of U.S. macroeconomic news. Throughout, news exerts a generally statistically significant influence on exchange rates, whereas expected announcements generally do not. That is, only unanticipated shocks to fundamentals affect exchange rates, in accordance with the

\footnotetext{
${ }^{14}$ The Japanese opening is at $8 \mathrm{pm}$ Eastern daylight savings time, the Japanese lunch hour is $11 \mathrm{pm}$ through 12:30 am Eastern daylight savings time, the U.S. late afternoon during daylight savings time is defined to start at $3 \mathrm{pm}$ Eastern daylight savings time.

${ }^{15}$ See Rao (1970) and Chesher and Jewitt (1987).
} 
predictions of rational expectations theory. Many U.S. indicators have statistically significant news effects across all currencies, including payroll employment, durable goods orders, trade balance, initial unemployment claims, NAPM index, retail sales, consumer confidence, and advance GDP.

The general pattern is one of very quick exchange rate conditional mean adjustment, characterized by a jump immediately following the announcement, and little movement thereafter. Favorable U.S. "growth news" tends to produce dollar appreciation, and conversely. This is consistent with a variety of models of exchange rate determination, from simple monetary models (e.g., Mark, 1995) to more sophisticated frameworks involving a U.S. central bank reaction function displaying a preference for low inflation (e.g., Taylor, 1993). ${ }^{16}$ One can see from the center panel of the first row of Figure 3, for example, that a one standard deviation U.S. payroll employment surprise tends to appreciate (if positive) or depreciate (if negative) the dollar against the DM by $0.16 \%{ }^{17}$ This is a sizeable move, from both statistical and economic perspectives. On the statistical side, we note that only $0.7 \%$ of our 5 -minute returns show an appreciation or depreciation bigger than $0.10 \%$. On the economic side, we note that $0.16 \%$ is also large relative to the average $\mathrm{DM} / \$$ spread, which tends to be around $0.06 \%$ during the period we study (see, Bessembinder, 1994, and Hasbrouck, 1999, Table 1).

It is important to note that, although closely timed news events are highly correlated, the correlation does not create a serious multicolinearity problem except in a few specific instances. For example, industrial production and capacity utilization are released at the same time, and they are highly correlated (0.64). In general, however, the event that two announcements within the same category (e.g., real activity) are released simultaneously is rare.

Now let us focus on the $\mathrm{DM} / \$$ rate in some detail. It is of particular interest both because of its central role in the international financial system during the period under study, and because we have news data on both U.S. and German macroeconomic indicators. ${ }^{18}$ First consider the effects of U.S. macroeconomic news on the DM/\$ rate. News announcements on a variety of U.S. indicators significantly affect the $\mathrm{DM} / \$$ rate, including payroll employment, durable goods orders, trade balance, initial claims, NAPM index, retail sales, consumer confidence, CPI, PPI, industrial production, leading

\footnotetext{
${ }^{16}$ For most of our macroeconomic indicators, including those on which we primarily focus, the sign of a "good shock" is clear: movements associated with increased real U.S. economic activity are good for the dollar.

Sometimes, however, it is not obvious which direction should be viewed as good, as perhaps with consumer credit.

${ }^{17}$ We interpret a one standard deviation surprise as "typical."

${ }^{18}$ German news are the only non-U.S. news that are readily available from MMS.
} 
indicators, housing starts, construction spending, federal funds rate, new home sales, and GDP (advance, preliminary and final).

Now consider the effect of German macroeconomic news on the DM/ $\$$ rate. ${ }^{19}$ In sharp contrast to the large number of U.S. macroeconomic indicators whose news affect the DM/ $\$$ rate, only very few of the German macroeconomic indicators have a significant effect (M3 and industrial production). We conjecture that the disparity may be due to the fact, detailed in Table 1, that the release times of U.S. macroeconomic indicators are known exactly (day and time) but only inexactly for Germany (day but not time). Uncertain release times may result in less market liquidity (and trading) around the announcement times, hence resulting in smaller news effects around the announcements, ultimately producing a more gradual adjustment, perhaps for a few hours after the announcements. Alternatively, greater preannouncement leakage in Germany may result in adjustments taking place gradually in the days prior to the actual announcement.

Most of the explanatory power of the exchange rate conditional mean model (1) comes from the lagged values of the dependent variable and the contemporaneous news announcement. Hence, although fifty-eight percent of the days in our sample contain a news announcement, to a good approximation the news predicts only the direction and magnitude of the exchange rate movement during the 5-minute postrelease intervals, which correspond to only two tenths of one percent of the sample observations. To focus on the the importance of news during announcement periods, we now estimate the model

$$
R_{t}=\beta_{k} S_{k t}+\varepsilon_{t}
$$

where $R_{t}$ is the 5-minute return from time $t$ to time $t+1$ and $S_{k t}$ is the standardized news corresponding to announcement $k(k=1, \ldots, 41)$ at time $t$, and the estimates are based on only those observations $\left(R_{t}, S_{k t}\right)$ such that an announcement was made at time $t$.

We show the estimation results in Table 3 , which contains a number of noteworthy features. First, news on many of the fundamentals exerts a significant influence on exchange rates. This is of course expected, given our earlier estimation results for equation (1) as summarized in Figure 3. News from FOMC deliberations, for example, clearly influences exchange rates: the large and statistically significant coefficients, and the high $R^{2} s$, are striking. Their positive signs indicate that, as expected for example in a standard monetary model, Fed tightening is associated with dollar appreciation. ${ }^{20}$

\footnotetext{
${ }^{19}$ To a first approximation, German news is relevant only for DM/\$ determination, in contrast to U.S. news, which is relevant for the determination of all U.S. dollar exchange rates.

${ }^{20}$ It would be interesting (with a longer sample of data) to examine the stability of the response coefficient over different stages of the business cycle; see, e.g., McQueen and Roley (1993). According to the standard U.S. business cycle chronology produced by the National Bureau of Economic Research, the U.S. was in an expansion
} 
Second, unlike the $R^{2}$ values for equation (1), which are typically very small, the $R^{2}$ values for equation (3) are often quite high. News announcements occur comparatively rarely and have a nonnegligible but short-lived impact on exchange rates; hence the $R^{2}$ in an equation such as (3) must be low when computed across all 5-minute observations. In contrast, one naturally expects higher $R^{2}$ values when computed using only announcement observations, although the precise size is of course an empirical matter. Table 3 reveals $R^{2}$ values that are often around 0.3 and sometimes approaching 0.6.

Finally, it is interesting to note that the results of Cheung and Chinn (2000,2001), obtained by surveying traders, cohere reassuringly with the model-based results documented here. In particular, Cheung and Chinn (2001) report that traders believe that exchange rates adjust almost instantaneously following news announcements, and that news regarding real variables is more influential than news regarding nominal variables, which is entirely consistent with the empirical results reported in Table 3.

\section{News Effects II: Announcement Timing Matters}

One might wonder whether, within the same general category of macroeconomic indicators, news on those released earlier tend to have greater impact than those released later. To evaluate this conjecture, we grouped the U.S. indicators into seven types: real activity, consumption, investment, government purchases, net exports, prices, and forward-looking. Within each group, we arranged the announcements in the chronological order described in Table 2. The conjecture is generally verified. In the estimates of equation (3) within each indicator group, the announcements released earliest tend to have the most statistically significant coefficients and the highest $R^{2}$ values. ${ }^{21}$ In Figure 4 we plot the $R^{2}$ of equation (3) within each indicator group, as a function of the announcement timing. The clearly prevalent downward slopes reveal that the early announcements do indeed have the greatest impact.

The fact that "announcement timing matters" helps with the interpretation of our earlier-reported empirical results in Table 3, which indicate that only seven of the forty announcements significantly impacted all the currency specifications. The reason is that many of the announcements are to some extent redundant, and the market then only reacts to those released earlier. Hence, for example, U.S. durable goods orders matter for all currency pairs but U.S. factory orders, which are released later, do not.

\section{News Effects III: Volatility Adjusts to News Gradually}

from March of 1991 until March of 2001; hence our entire sample.

${ }^{21}$ One exception is the nominal group; the consumer price index seems more important than the producer price index, despite its earlier release date. 
As discussed previously and documented in Figure 3, exchange rates adjust to news immediately. It is interesting to note, however, that exchange rate volatilities adjust only gradually, with complete adjustment occurring only after $J^{\prime}=125$-minute periods, or one hour.

We provide details in Table 4. As already noted, and as shown again in the top panel of the table, the contemporaneous return response coefficients are sizeable and statistically significant, and the full response occurs immediately. In contrast, the contemporaneous volatility response coefficients, although statistically significant, are smaller, as shown in the middle panel of the table. Importantly, however, the complete response of volatility to news occurs only after an hour or so, and it is noticeably larger than either the contemporaneous volatility response or the contemporaneous return response, as shown in the bottom panel of the table.

\section{News Effects IV: Pure Announcement Effects are Present in Volatility}

It is possible that the mere presence of an announcement might boost volatility, quite apart from the size of the associated surprise. To explore this possibility we add to the returns equation (1) $J$ lags of announcement period dummies on each of $K$ fundamentals, and we also add to the volatility equation (2) $J$ ' lags of announcement period dummies on each of $K$ fundamentals. As shown in Table 5, the announcement dummies are generally insignificant in the returns equation (1) but generally significant in the volatility equation (2), in line with earlier results for bond markets such as Fleming and Remolona (1997, 1999). News effects are still important, however, in both conditional mean and variance dynamics.

\section{News Effects V: Announcement Effects are Asymmetric - Responses Vary with the Sign of the News}

We have seen that news about macroeconomic fundamentals significantly affect high-frequency exchange rates. Thus far we have allowed only for constant news effects, but it is natural to go farther and ask whether the news effects vary with the sign of the surprise. To address this issue we generalize equation (3) by allowing the impact response coefficient $\beta_{k}$ to be a linear function of the news surprise $S_{k t}$, allowing for a different constant and slope on each side of the origin,

$$
\beta_{k}= \begin{cases}\beta_{0 k}+\beta_{1 k} S_{k t} & \text { if } S_{t} \leq 0 \\ \beta_{2 k}+\beta_{3 k} S_{k t} & \text { if } S_{t}>0 .\end{cases}
$$

Inserting (4) into (3) yields the impact response specification,

$$
R_{t}= \begin{cases}\beta_{0 k} S_{k t}+\beta_{1 k} S_{k t}^{2}+\varepsilon_{t} & \text { if } S_{t} \leq 0 \\ \beta_{2 k} S_{k t}+\beta_{3 k} S_{k t}^{2}+\varepsilon_{t} & \text { if } S_{t}>0 .\end{cases}
$$


Following Engle and $\mathrm{Ng}$ (1993), we call the union of $\beta_{0 k} S_{k t}+\beta_{1 k} S_{k t}^{2}$ to the left of the origin and $\beta_{2 k} S_{k t}+\beta_{3 k} S_{k t}^{2}$ to the right of the origin the "news impact curve." 22 In the top row of Figure 5 we show the news impact curves averaged across all macroeconomic fundamentals, $k=1, \ldots, 41$. It is clear that, on average, the effect of macroeconomic news often varies with its sign. In particular, negative surprises often have greater impact than positive surprises. ${ }^{23}$

It is interesting to see whether the sign effect prevails when we look separately at the most important news announcements. In the remaining rows of Figure 5 we show the news impact curves for payroll employment, trade balance, durable goods orders and initial claims. The sign effect is generally maintained, although there is some variation across indicators and currencies. Asymmetry in the Yen $/ \$$, $\mathrm{DM} / \$$ and $\mathrm{CHF} / \$$ response to payroll employment and trade balance news, for example, is very pronounced, whereas it is largely absent in the Pound $/ \$$ and Euro $/ \$$ response.

In the next section we explore more deeply the economics behind the asymmetric response. Recent theoretical models suggest that the asymmetry may be driven, in part, by the dynamics of uncertainty regarding the underlying state of the economy. It turns out that our MMS dataset contains not only expectations, but also a measure of the cross-sectional dispersion of expectations, the standard deviation. Using the cross-sectional standard deviation as a proxy for state uncertainty, we can therefore directly assess a key mechanism thought to generate asymmetric response, to which we now turn.

\section{Asymmetric Response, Information Processing and Price Discovery}

Two strands of literature imply asymmetry in the response of exchange rates to news. In particular, they imply that bad news in "good times" should have an unusually large impact, a view that is also common in the practitioner community, as emphasized by Conrad, Cornell, and Landsman (2001). Note that our entire sample takes place in good times - 1992 through 1998. Hence the theoretical prediction that "bad news in good times should have unusually large effects," degenerates in our sample

\footnotetext{
${ }^{22}$ Despite the superficial resemblance in terms of documenting asymmetric responses to news, our work is very different from that of Engle and $\mathrm{Ng}$ (1993) and many subsequent related studies. In particular, the Engle-Ng news impact curve tracks the variance of equity returns conditional upon the sign and size of past returns (with no allowance for a time-varying conditional mean return), whereas our news impact curve tracks the mean of foreign exchange returns conditional upon the sign and size of macroeconomic news.

${ }^{23}$ To the best of our knowledge, such sign effects have not previously been documented for the foreign exchange market. Evidence of asymmetric conditional-mean news effects exists in other contexts, however. For example, Conrad, Cornell and Landsman (2001) find asymmetric effects of earnings news on stock returns, while recent concurrent work by Hautsch and Hess (2001) details an asymmetric response to employment news in the T-bond futures market.
} 
period to "bad news should have unusually large effects," which, to a reasonably good approximation, is what we found earlier.

The first strand of the literature is "behavioral" and focuses primarily on equities, at the firm level. Barberis, Shleifer and Vishy (1998), for example, model investors as believing that firm earnings follow a two-state regime-switching process - erroneously, as earnings actually follow a random walk with mean-reverting earnings in state 0 and upward trending earnings in state 1 . Hence a series of positive earnings leads investors to infer that state 1 holds, with the concomitant expectation of additional positive earnings. In such a situation, bad news generates a large negative response because it is a surprise, whereas good news generates little response because it is anticipated.

The second relevant strand of the literature uses a rational expectations equilibrium approach and focuses more on the market level as opposed to the firm level, as in Veronesi (1999), David and Veronesi (2001), and Johnson (2000, 2001). Veronesi (1999), in particular, models investors as (correctly) believing that the economy follows a two-state regime-switching process, with "low" and "high" states corresponding to recessions and expansions. Agents solve a signal extraction problem to determine the probability $\pi(t)$ of being in the high state, and equilibrium asset prices can be shown to be increasing and convex functions of $\pi(t)$. The intuition for this key result is simple. Suppose that $\pi(t-1) \approx 1$, i.e., investors believe that the high state almost surely prevails. Then if bad news arrives at time $t$, two things happen: first, expected future asset values decrease, and second, $\pi(t)$ decreases (i.e., state risk increases). Risk-averse investors require additional returns for bearing this additional risk; hence they require an additional discount on the asset price, which drops by more than it would in a present-value model. Conversely, suppose investors are confident that the low state prevails, i.e., $\pi(t-1) \approx 0$. Then if good news arrives at time $t$, expected future asset values increase, but $\pi(t)$ also increases (i.e., state risk again increases). As before, investors require additional returns for bearing this additional risk; hence they require a discount on the asset price, which increases by less than it would in a present-value model.

For a number of reasons, it is not our intention here to explicitly test the practitioner claim that prices respond most strongly to bad news in good times, or to directly implement Veronesi's model or to combine it with the Barberis-Shleifer-Vishy model. First, our dataset is not well-suited to that purpose; as mentioned above, it contains only the expansionary 1990s. Second, Conrad, Cornell and Landsman (2001) have already made admirable progress in that regard, finding general support for the assertion that (stock) prices respond most strongly to bad news in good times. Third, the Barberis-Schleifer-Vishny model is not particularly well-suited to the forex context relevant here, as it focuses on the earnings stream for an individual firm. 
Instead, we take as true the practitioner claim that prices respond most strongly to bad news in good times, and we focus on the explanation embodied in Veronesi's model. We use an interesting feature of our MMS expectations data to assess the key alleged mechanism through which bad news in good times translates into large price moves: increased uncertainty about the state of the economy. In particular, we have data not only on the median expectations of macroeconomic fundamentals, but also on the associated standard deviations across the individual forecasters. Hence we can check directly whether uncertainty about the state of the economy, as proxied by the standard deviation of expectations across the individual forecasters, increases following the arrival of bad news in good times. ${ }^{24}$ Before proceeding to examine the effect of bad news arrivals on subsequent forecast dispersion, however, two issues arise.

First, it is not clear what timing in the data matches the generic timing in the model. Clearly, bad news at time $\mathrm{t}-1$ means that expectations for time $\mathrm{t}$ are formed in a bad news environment, but what if the news at $\mathrm{t}-2$ was bad and the news at $\mathrm{t}-1$ was not? Perhaps agents have a memory that lasts longer than one announcement period, so that even the latter case could be viewed as a bad news environment. In general, we might say that we are in a bad news environment if the news was bad at any of times $\mathrm{t}-1, \mathrm{t}-2$, ..., t-d, for some d. Second, to enhance our chances of detecting the "Veronesi effect," if it exists, we may not want to track the arrival of all bad news, but rather only bad news that exceeds some minimal threshold, say the $p$-th percentile of the distribution of bad news, where $p$, like $d$, must be chosen. As a benchmark, we simply set $\mathrm{d}=1$ and $\mathrm{p}=50 \%$ (i.e., the median).

Figure 6 plots the corresponding standard deviation of the MMS payroll employment, durable goods orders and trade balance forecasts. The shaded areas indicate a bad news environment using the criteria $\mathrm{d}=1$ and $\mathrm{p}=50 \%$. Analyst forecast dispersion is indeed higher following bad news than at other times; specifically, the uncertainty of payroll employment is thirty percent higher, the uncertainty of durable goods orders is six percent higher, and the uncertainty of the trade balance is twelve percent higher. These effects are robust to reasonable variation in $\mathrm{p}$ and $\mathrm{d}$.

\section{Concluding Remarks and Directions for Future Research}

The goal of the research on which this paper reports is to deepen our understanding of the links between exchange rate movements and news about fundamentals. To that end, in this paper we have documented important news effects, with asymmetric response patterns. Let us conclude by relating our results to work on order flow and drawing implications for future research.

\footnotetext{
${ }^{24}$ Of course, the notion of forecast uncertainty and the forecast dispersion across forecasters are not exactly equivalent concepts. Zarnowitz and Lambros (1987) show, however, that they are generally positively correlated.
} 
In recent innovative work, Evans and Lyons (2002) show that signed order flow is a good predictor of subsequent exchange rate movements. This work is important in that it enhances our understanding of the determinants of high-frequency exchange rate movements, but less satisfying in that it remains ignorant about the determinants of high-frequency order flow. We, in contrast, have shown that news affects exchange rates. Combining our perspectives focuses attention on the causal links among news, order flow and forex movements, which in our view is a prime candidate for future research. It will be of interest, for example, to determine whether news affects exchange rates via order flow or instantaneously. ${ }^{25}$ In work done subsequently to the first draft of this paper, Evans and Lyons (2001) and Froot and Ramadorai (2001) tackle precisely that issue.

A second key direction for future research is pushing farther with the implications of Veronesi (1999) for the analysis of high-frequency news effects. Presently we have verified that the key mechanism that amplifies the effects of bad news in good times in Veronesi's model - increased state uncertainty - is operative in the data. However, one could potentially go farther and exploit the broader implications of Veronesi's work for our approach, namely that news effects are in general a function of state uncertainty, by including interactions of news with state uncertainty in both our conditional mean and conditional variance specifications. This would be particularly interesting if data were available on exchange rates and fundamentals spanning bad as well as good times, but as of this writing, such data remain elusive.

Third, it would be of interest to explore not only the effects of regularly-scheduled quantitative news on macroeconomic fundamentals, but also the effects of irregularly-scheduled, qualitative "headline news," as prices, and perhaps order flow, may reasonably be expected to respond to both. ${ }^{26}$ It is not obvious, however, how to do so in a compelling way; both the conceptual and the practical complications seem daunting.

Fourth, it will be of interest to attempt an analysis of structural stability, as the market may change its view about which news is important for exchange rates, or about how to interpret the sign of a surprise. In some interpretations, for example, a positive U.S. inflation surprise would tend to produce dollar depreciation (e.g., when the U.S. central bank reaction function assigns relatively low weight to the

\footnotetext{
${ }^{25}$ For instance, French and Roll (1986) and Fleming and Remolona (1999) both argue that publicly available news may be incorporated in prices instantaneously, even without trading.

${ }^{26}$ Indirect evidence is provided by Eddelbüttel and McCurdy (1998), who report significantly heightened foreign exchange rate volatility in response to the mere frequency of headline news items on the Reuters News screen.
}

$-18-$ 
level of inflation), whereas in other interpretations it would produce dollar appreciation (e.g., when the U.S. central bank reaction function shows strong preference for low inflation, as in Taylor, 1993).

Finally, we look forward to characterizing the joint responses of the foreign exchange, stock and bond markets to real-time news surprises. Responses have now been studied for each market in isolation: Fleming and Remolona (1999) and Balduzzi, Elton and Green (2001) study the bond market, Flannery and Protopapadakis (2001) study the stock market, and this paper of course studies the foreign exchange market. A multivariate framework, however, will facilitate analysis of cross-market movements and interactions, or lack thereof, which may for example shed light on agents' views regarding central bank reaction functions. 


\section{References}

Almeida, A., Goodhart, C. and Payne, R. (1998), "The Effects of Macroeconomic'News' on High Frequency Exchange Rate Behavior," Journal of Financial and Quantitative Analysis, 33, 383408.

Andersen, T.G. and Bollerslev, T. (1998), "Deutsche Mark-Dollar Volatility: Intraday Activity Patterns, Macroeconomic Announcements, and Longer Run Dependencies,” Journal of Finance, 53, 219265.

Andersen, T.G., Bollerslev, T., Diebold, F.X. and Ebens, H. (2001), "The Distribution of Realized Stock Return Volatility," Journal of Financial Economics, 61, 43-76.

Andersen, T.G., Bollerslev, T., Diebold, F.X. and Labys, P. (2001a), "The Distribution of Realized Exchange Rate Volatility," Journal of the American Statistical Association, 94, 42-55.

Andersen, T.G., Bollerslev, T., Diebold, F.X. and Labys, P. (2001b), "Modeling and Forecasting Realized Volatility," NBER Working Paper 8160.

Barberis, N., Shleifer, A. and Vishny, R. (1998), “A Model of Investor Sentiment,” Journal of Financial Economics, 49, 307-343.

Balduzzi, P., Elton, E.J. and Green, T.C. (1998), "Economic News and the Yield Curve: Evidence From the U.S. Treasury Market," Salomon Center Working Paper S-98-5, Stern School of Business, New York University.

Balduzzi, P., Elton, E.J. and Green, T.C. (2001), "Economic News and Bond Prices: Evidence From the U.S. Treasury Market," Journal of Financial and Quantitative Analysis, forthcoming.

Bessembinder, H. (1994), "Bid-Ask Spreads in the Interbank Foreign Exchange Market," Journal of Financial Economics, 35, 317-348.

Bollerslev, T., Cai, J. and Somg, F.M. (2000), "Intraday Periodicity, Long-Memory Volatility, and Macroeconomic Announcement Effects in the U.S. Treasury Bond Market," Journal of Empirical Finance, 7, 37-55.

Bollerslev, T., Chou, R.Y. and Kroner, K.F. (1992), “ARCH Modeling in Finance: A Selective Review of the Theory and Empirical Evidence," Journal of Econometrics, 52, 5-59.

Bollerslev, T. and Domowitz, I. (1993), "Trading Patterns and Prices in the Interbank Foreign Exchange Market," Journal of Finance, 48, 1421-1443.

Brandt, M.W., Edelen, R. and Kavajecz, K.A. (2001), "Liquidity in the U.S. Treasury Market: Asymmetric Information and Inventory Effects,” Manuscript, University of Pennsylvania.

Chesher, A. and Jewitt, I. (1987), "The Bias of a Heteroskedasticity Consistent Covariance Matrix Estimator," Econometrica, 55, 1217-1222.

Cheung, Y.-W. and Chinn, M.D. (2000), “A Survey of Market Practitioners' Views on Exchange Rate Dynamics," Journal of International Economics, 51, 401-419. 
Cheung, Y.-W. and Chinn, M.D. (2001), "Currency Traders and Exchange Rate Dynamics: A Survey of the U.S. Market," Journal of International Money and Finance, 20, 439-471.

Conrad, J., Cornell, B. and Landsman, W. (2001), "When is Bad News Really Bad News?," Working Paper, University of North Carolina, Chapel Hill.

Dacorogna, M.M., Müller, U.A., Nagler, R.J., Olsen, R.B. and Pictet, O.V. (1993), “A Geographical Model for the Daily and Weekly Seasonal Volatility in the Foreign Exchange Market," Journal of International Money and Finance, 12, 413-438.

Danielsson, J. and Payne, R. (1999), "Real Trading Patterns and Prices in Spot Foreign Exchange Markets," Manuscript, London School of Economics.

David, Alexander and Pietro Veronesi (2001), "Inflation and Earnings Uncertainty and the Volatility of Asset Prices: An Empirical Investigation," Working Paper.

Diebold, F.X. and Lopez, J. (1995), “Modeling Volatility Dynamics,” in Kevin Hoover (ed.), Macroeconometrics: Developments, Tensions and Prospects, 427-472, 1995. Boston: Kluwer Academic Press.

Dominguez, K.M. (1999), “The Market Microstructure of Central Bank Intervention,” NBER Working Paper 7337.

Engle, R.F. and Ng, V.K. (1993), "Measuring and Testing the Impact of News in Volatility," Journal of Finance, 48, 1749-1778.

Eddelbüttel, D. and McCurdy, T.H. (1998), "The Impact of News on Foreign Exchange Rates: Evidence from High Frequency Data,” Manuscript, Rotman School of Management, University of Toronto.

Ederington L. and Lee, J. (1993), "How Markets Process Information: News Releases and Volatility," Journal of Finance, 48, 1161-1191.

Evans, M.D.D. and Lyons, R.K. (2001), “Why Order Flow Explains Exchange Rates,” Manuscript, University of California, Berkeley.

Evans, M.D.D. and Lyons, R.K. (2002), “Order Flow and Exchange Rate Dynamics,” Journal of Political Economy, 110, 170-180.

Flannery, M. J. and Protopapadakis, A. (2001), "Macroeconomic Factors do Influence Aggregate Stock Returns," Review of Financial Studies, forthcoming.

Fleming, M.J. and Remolona, E.M. (1997), "What Moves the Bond Market," Economic Policy Review, Federal Reserve Bank of New York, 3 (December), 31-50.

Fleming, M.J. and Remolona, E.M. (1999), "Price Formation and Liquidity in the U.S. Treasury Market: The Response to Public Information," Journal of Finance, 54, 1901-1915.

Frankel, J.A. and Rose, A.K. (1995), "A Survey of Empirical Research on Nominal Exchange Rates," in G. Grossman and K. Rogoff (eds.), Handbook of International Economics. Amsterdam: NorthHolland, 1995. 
French, K.F. and Roll, R. (1986), "Stock Return Variances: The Arrival of Information and the Reaction of Traders," Journal of Financial Economics, 17, 5-26.

Froot, K.A. and Ramadorai, T. (2001), "Currency Returns, Institutional Investor Flows, and ExchangeRate Fundamentals," Manuscript, Harvard University.

Gallant, A.R. (1981), "On the Bias in Flexible Functional Forms and an Essentially Unbiased Form: The Fourier Flexible Form," Journal of Econometrics, 15, 211-245.

Goodhart, C.A.E., Hall, S.G., Henry S.G.B. and Pesaran, B. (1993), "News Effects in a High-Frequency Model of the Sterling-Dollar Exchange Rate," Journal of Applied Econometrics, 7, 199-211.

Goodhart, C., Ito, T. and Payne, R. (1996), "One Day in June 1993: A Study of the Working of the Reuters 2000-2 Electronic Foreign Exchange Trading System," in J.A. Frankel, G. Galli and A. Giovannini (eds.) The Microstructure of Foreign Exchange Markets, 107-179. Chicago: University of Chicago Press for NBER.

Harvey, C.R. and Huang, R.D. (2002), “The Impact of the Federal Reserve Bank's Open Market Operations," Journal of Financial Markets, 5, 223-257.

Hasbrouck, J. (1999), "Security Bid/Ask Dynamics with Discreteness and Clustering: Simple Strategies for Modeling and Estimation," Journal of Financial Markets, 2, 1-28.

Hautsch, N. and Hess, D. (2001), "What's Surprising about Surprises? The Simultaneous Price and Volatility Impact of Information Arrival," Manuscript, Center for Finance and Econometrics, University of Konstanz, Germany.

Johnson, T.C. (2000), "Return Dynamics When Persistence is Unobservable," Manuscript, London Business School.

Johnson, T.C. (2001), "Volatility, Momentum, and Time Varying Skewness in Foreign Exchange Returns," Manuscript, London Business School.

Kuttner, K.N. (2001), "Monetary Policy Surprises and Interest Rates: Evidence from the Fed Funds Futures Market," Journal of Monetary Economics, 47, 523-544.

Mark, N.C. (1995), "Exchange Rates and Fundamentals: Evidence on Long-Horizon Predictability," American Economic Review, 85, 201-218.

Mark, N.C. and Sul, D. (1998), "Nominal Exchange Rates and Monetary Fundamentals: Evidence From a Small Post-Bretton-Woods Panel," Manuscript, Ohio State University.

McQueen, G. and Roley, V.V. (1993), "Stock Prices, News, and Business Conditions," Review of Financial Studies, 6, 683-707.

Meese, R. and Rogoff, K. (1983), "Empirical Exchange Rate Models of the Seventies: Do They Fit Out of Sample?," Journal of International Economics, 14, 3-24. 
Müller, U.A., Dacorogna, M.M., Olsen, R.B., Pictet, O.V., Schwarz, M. and Morgenegg, C. (1990), "Statistical Study of Foreign Exchange Rates, Empirical Evidence of a Price Change Scaling Law, and Intraday Analysis," Journal of Banking and Finance, 14, 1189-1208.

Payne, R. (1996), “Announcement Effects and Seasonality in the Intra-day Foreign Exchange Market," Working Paper, London School of Economics.

Pearce, D.K. and Roley, V.V. (1985), "Stock Prices and Economic News," Journal of Business, 58, 4967.

Rao, C.R. (1970), "Estimation of Heteroskedastic Variances in Linear Models," Journal of the American Statistical Association, 65, 161-172.

Rudebusch, G.D. (1998), “Do Measures of Monetary Policy in a VAR Make Sense?,” International Economic Review, 39, 907-931.

Taylor, J.B. (1993), "Discretion Versus Policy Rules in Practice," Carnegie-Rochester Conference Series on Public Policy, 39, 195-214.

Urich, T. and Wachtel, P. (1984), “The Effects of Inflation and Money Supply Announcements on Interest Rates," Journal of Finance, 39, 1177-1188.

Veronesi, P. (1999), "Stock Market Overreaction to Bad News in Good Times: A Rational Expectations Equilibrium Model," Review of Financial Studies, 12, 975-1007.

Zarnowitz, V. and Louis A. Lambros, (1987), "Consensus and Uncertainty in Economic Prediction," Journal of Political Economy, 95, 591-621. 
Table 1

U.S. News Announcements

\begin{tabular}{|c|c|c|c|c|}
\hline Announcement & Obs. ${ }^{1}$ & Source $^{2}$ & Dates $^{3}$ & Announcement Time $^{4}$ \\
\hline \multicolumn{5}{|c|}{ Quarterly Announcements } \\
\hline 1- GDP Advance & 47 & BEA & $05 / 22 / 87-10 / 30 / 98$ & $8: 30 \mathrm{am}$ \\
\hline 2- GDP Preliminary & 46 & BEA & $06 / 17 / 87-12 / 23 / 98$ & $8: 30 \mathrm{am}$ \\
\hline 3- GDP Final & 47 & BEA & $01 / 22 / 87-11 / 24 / 98$ & $8: 30 \mathrm{am}$ \\
\hline \multicolumn{5}{|c|}{ Monthly Announcements } \\
\hline \multicolumn{5}{|l|}{ Real Activity } \\
\hline 4- Nonfarm Payroll Employment & 144 & BLS & $12 / 05 / 86-12 / 04 / 98^{5}$ & $8: 30 \mathrm{am}$ \\
\hline 5- Retail Sales & 145 & $\mathrm{BC}$ & $12 / 11 / 86-12 / 11 / 98$ & $8: 30 \mathrm{am}$ \\
\hline 6- Industrial Production & 145 & FRB & $12 / 15 / 86-12 / 16 / 98$ & $9: 15 \mathrm{am}$ \\
\hline 7- Capacity Utilization & 145 & FRB & $12 / 15 / 86-12 / 16 / 98$ & $9: 15 \mathrm{am}$ \\
\hline 8- Personal Income & 142 & BEA & $12 / 18 / 86-12 / 24 / 98^{6}$ & $10: 00 / 8: 30 \mathrm{am}^{7}$ \\
\hline 9- Consumer Credit & 129 & FRB & $04 / 04 / 88-12 / 07 / 98$ & $3: 00 \mathrm{pm}^{8}$ \\
\hline \multicolumn{5}{|l|}{ Consumption } \\
\hline 10- Personal Consumption Expenditures & 143 & BEA & $12 / 18 / 86-12 / 24 / 98^{9}$ & $10: 00 / 8: 30 \mathrm{am}^{10}$ \\
\hline $\begin{array}{l}\text { 11- New Home Sales } \\
\text { Investment }\end{array}$ & 117 & $\mathrm{BC}$ & $03 / 02 / 89-12 / 02 / 98$ & 10:00 am \\
\hline 12- Durable Goods Orders & 143 & $\mathrm{BC}$ & $12 / 23 / 86-12 / 23 / 98^{11}$ & 8:30/9:00/10:00 $\mathrm{am}^{12}$ \\
\hline 13- Construction Spending & 128 & $\mathrm{BC}$ & $04 / 01 / 88-12 / 01 / 98^{13}$ & 10:00 am \\
\hline 14- Factory Orders & 127 & $\mathrm{BC}$ & $03 / 30 / 88-12 / 04 / 98^{14}$ & 10:00 am \\
\hline 15- Business Inventories & 129 & $\mathrm{BC}$ & $04 / 14 / 88-12 / 15 / 98$ & $10: 00 / 8: 30 \mathrm{am}^{15}$ \\
\hline \multicolumn{5}{|l|}{ Government Purchases } \\
\hline $\begin{array}{l}\text { 16- Government Budget Deficit } \\
\text { Net Exports }\end{array}$ & 124 & FMS & $04 / 21 / 88-12 / 21 / 98^{16}$ & $2: 00 \mathrm{pm}$ \\
\hline $\begin{array}{l}\text { 17- Trade Balance } \\
\text { Prices }\end{array}$ & 128 & BEA & $04 / 14 / 88-12 / 17 / 98$ & $8: 30 \mathrm{am}$ \\
\hline 18- Producer Price Index & 145 & BLS & $12 / 12 / 86-12 / 11 / 98$ & $8: 30 \mathrm{am}$ \\
\hline 19- Consumer Price Index & 145 & BLS & $12 / 19 / 86-12 / 15 / 98$ & $8: 30 \mathrm{am}$ \\
\hline \multicolumn{5}{|l|}{ Forward-Looking } \\
\hline 20- Consumer Confidence Index & 90 & $\mathrm{CB}$ & $07 / 30 / 91-12 / 29 / 98$ & $10: 00 \mathrm{am}$ \\
\hline 21- NAPM Index & 107 & NAPM & 02/01/90-10/01/98 & 10:00 am \\
\hline 22- Housing Starts & 145 & $\mathrm{BC}$ & $12 / 30 / 86-12 / 30 / 98$ & $8: 30 \mathrm{am}$ \\
\hline 23- Index of Leading Indicators & 145 & $\mathrm{CB}$ & $12 / 30 / 86-12 / 30 / 98$ & $8: 30 \mathrm{am}$ \\
\hline \multicolumn{5}{|c|}{ Six-Week Announcements } \\
\hline \multicolumn{5}{|l|}{ FOMC } \\
\hline 24- Target Federal Funds Rate & 62 & FRB & 2/5/92-12/22/98 & $2: 15 \mathrm{pm}^{17}$ \\
\hline \multicolumn{5}{|c|}{ Weekly Announcements } \\
\hline 25- Initial Unemployment Claims & 384 & ETA & $07 / 18 / 91-12 / 31 / 98$ & $8: 30$ am \\
\hline 26- Money Supply, M1 & 628 & FRB & $12 / 04 / 86-12 / 31 / 98$ & $4: 30 \mathrm{pm}$ \\
\hline 27- Money Supply, M2 & 563 & FRB & $03 / 03 / 88-12 / 31 / 98$ & $4: 30 \mathrm{pm}$ \\
\hline 28- Money Supply, M3 & 563 & FRB & $03 / 03 / 88-12 / 31 / 98$ & $4: 30 \mathrm{pm}$ \\
\hline
\end{tabular}


Table 1 (continued)

German News Announcements ${ }^{18}$

\begin{tabular}{|c|c|c|c|c|}
\hline Announcement & Obs. $^{1}$ & Source $^{2}$ & Dates $^{3}$ & Announcement Time ${ }^{4}$ \\
\hline \multicolumn{5}{|c|}{ Quarterly Announcements } \\
\hline 29- GDP & 24 & GFSO & 03/09/93-12/03/98 & Varies \\
\hline \multicolumn{5}{|c|}{ Monthly Announcements } \\
\hline \multicolumn{5}{|l|}{ Real Activity } \\
\hline 30- Employment & 59 & FLO & $04 / 06 / 93-12 / 08 / 98$ & Varies \\
\hline 31- Retail Sales & 59 & GFSO & $04 / 14 / 93-12 / 10 / 98$ & Varies \\
\hline $\begin{array}{l}\text { 32- Industrial Production } \\
\text { Investment }\end{array}$ & 63 & GFSO & 05/04/93-12/07/98 & Varies \\
\hline 33- Manufacturing Orders & 62 & GFSO & $04 / 06 / 93-12 / 07 / 98$ & Varies \\
\hline $\begin{array}{l}\text { 34- Manufacturing Output } \\
\text { Net Exports }\end{array}$ & 64 & GFSO & $03 / 02 / 93-12 / 07 / 98$ & Varies \\
\hline 35- Trade Balance & 61 & GFSO & $07 / 13 / 93-12 / 11 / 98$ & Varies \\
\hline 36- Current Account & 61 & BD & $07 / 13 / 93-12 / 11 / 98$ & Varies \\
\hline Prices & & & & \\
\hline 37- Consumer Price Index & 68 & GFSO & 03/01/93-12/23/98 & Varies \\
\hline 38- Producer Prices & 65 & GFSO & $03 / 18 / 93-12 / 22 / 98$ & Varies \\
\hline 39- Wholesale Price Index & 68 & GFSO & $03 / 16 / 93-12 / 16 / 98$ & Varies \\
\hline 40- Import Prices & 68 & GFSO & $03 / 26 / 93-12 / 21 / 98$ & Varies \\
\hline Monetary & & & & \\
\hline 41- Money Stock M3 & 66 & $\mathrm{BD}$ & 03/18/93-12/18/98 & Varies \\
\hline
\end{tabular}

Notes: We group the U.S. monthly news announcements into seven groups: Real activity, the four components of GDP (consumption, investment, government purchases and net exports), prices, and forward-looking. Within each group, we list U.S. news announcements in chronological order.

Footnotes:

1. Total number of observations in the announcements sample.

2. Bureau of Labor Statistics (BLS), Bureau of the Census (BC), Bureau of Economic Analysis (BEA), Federal Reserve Board

(FRB), National Association of Purchasing Managers (NAPM), Conference Board (CB), Financial Management Office

(FMO), Employment and Training Administration (ETA), German Federal Statistical Office (GFSO, Statistisches

Bundesamt Deutschland), Federal Labor Office (FLO, Bundesanstalt für Arbeit), Bundesbank (BD).

3. Starting and ending dates of the announcements sample.

4. Eastern Standard Time. Daylight savings time starts on the first Sunday of April and ends on the last Sunday of October.

5. $10 / 98$ is a missing observation.

6. $11 / 95,2 / 96$ and $03 / 97$ are missing observations.

7. In 01/94, the personal income announcement time moved from 10:00 am to 8:30 am.

8. Beginning in 01/96, consumer credit was released regularly at 3:00 pm. Prior to this date the release times varied.

9. $11 / 95$ and $2 / 96$ are missing observations.

10. In 12/93, the personal consumption expenditures announcement time moved from 10:00 am to 8:30 am.

11. $03 / 96$ is a missing observation.

12. Whenever GDP is released on the same day as durable goods orders, the durable goods orders announcement is moved to 10:00 am. On 07/96 the durable goods orders announcement was released at 9:00 am.

13. $01 / 96$ is a missing observation.

14. $10 / 98$ is a missing observation.

15. In 01/97, the business inventory announcement was moved from 10:00 am to 8:30 am.

16. $05 / 88,06 / 88,11 / 98,12 / 89$ and $01 / 96$ are missing observations.

17. Beginning in $3 / 28 / 94$, the fed funds rate was released regularly at $2: 15 \mathrm{pm}$. Prior to this date the release times varied.

18. Prior to 1994 the data refer only to West Germany. Beginning in 1994, the data refer to the unified Germany. The timing of the German announcements is not regular, but they usually occur between 2:00 am and 8:00 am Eastern Standard Time. 
Table 2

U.S. Macroeconomic Announcement Release Dates

Data for Month X

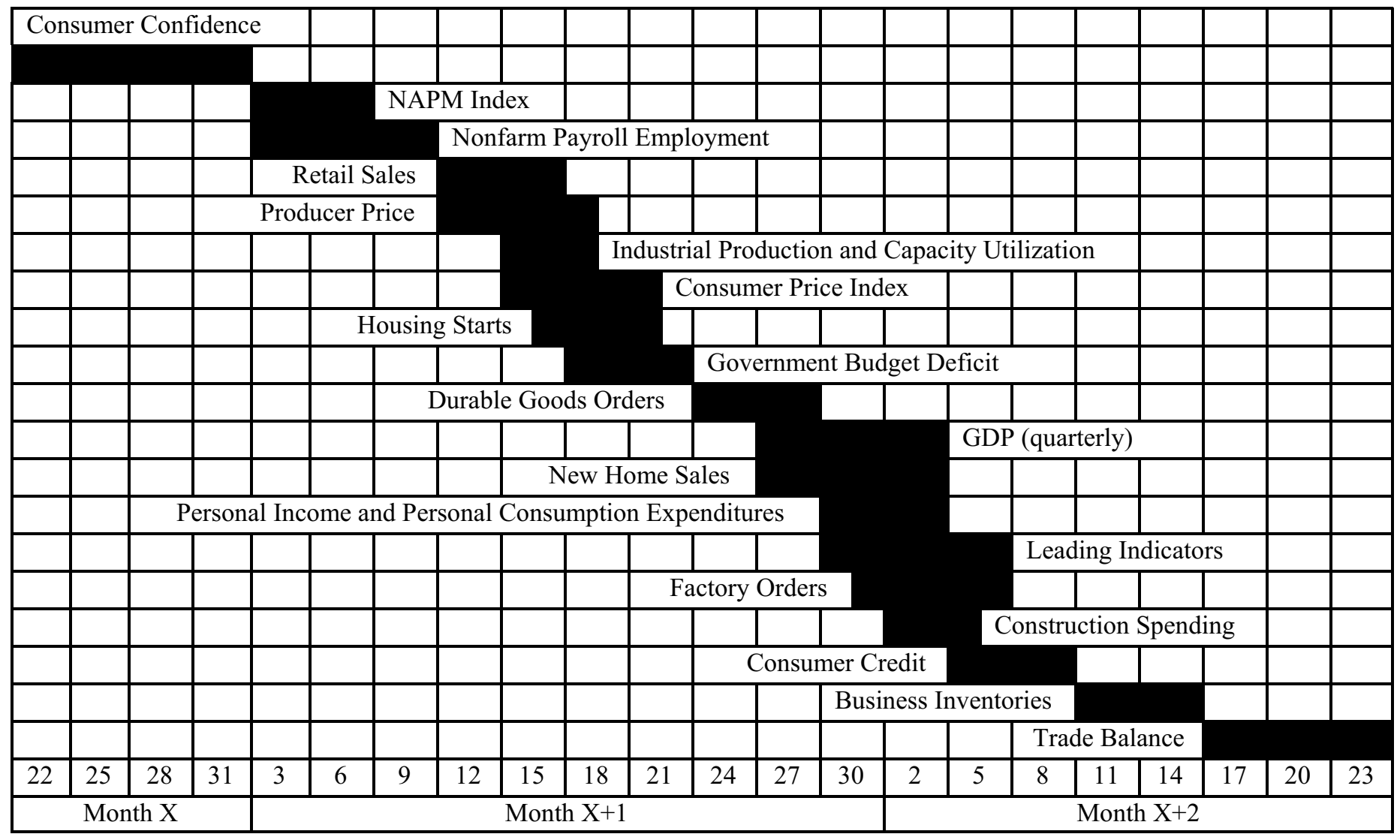

Notes: We show the sequence of announcement dates corresponding to data for month $\mathrm{X}$, for most of the economic indicators used in the paper. For example, March (month X) consumer credit data are announced between May (month $\mathrm{X}+2) 5$ and May 10. GDP data are special, because they are released only quarterly. Hence, the GDP data released in a given month are either advance, preliminary or final depending on whether the month is the first, second or third of the quarter. For example, first quarter Q1 GDP advance data are announced between April (month X+1) 27 and May 4, first quarter GDP preliminary data are announced between May (month X+2) 27 and June 4, and first quarter GDP final data are announced between June (month X+3) 27 and July 4. The table is based on 2001 Schedule of Release Dates for Principal Federal Economic Indicators, produced by the U.S. Office of Management and Budget and available at http://clinton4.nara.gov/textonly/OMB/pubpress/pei2001.html. 
Table 3

U.S. Contemporaneous News Response Coefficients and $R^{2}$ Values

\begin{tabular}{|c|c|c|c|c|c|c|c|c|c|c|}
\hline \multirow[b]{2}{*}{ Announcement } & \multicolumn{2}{|c|}{ Pound $/ \$$} & \multicolumn{2}{|c|}{ Yen $/ \$$} & \multicolumn{2}{|c|}{$\mathrm{DM} / \$$} & \multicolumn{2}{|c|}{$\mathrm{CHF} / \$$} & \multicolumn{2}{|c|}{ Euro/\$ } \\
\hline & $\beta_{k}$ & $R^{2}$ & $\beta_{k}$ & $R^{2}$ & $\beta_{k}$ & $R^{2}$ & $\beta_{k}$ & $R^{2}$ & $\beta_{k}$ & $R^{2}$ \\
\hline & \multicolumn{10}{|c|}{ Quarterly Announcements } \\
\hline 1- GDP Advance & 0.029 & 0.098 & 0.036 & 0.102 & $0.08^{*}$ & 0.301 & $0.079^{*}$ & 0.307 & $0.061 *$ & 0.420 \\
\hline 2- GDP Preliminary & 0.038 & 0.134 & 0.022 & 0.081 & $0.055^{*}$ & 0.185 & $0.057^{*}$ & 0.207 & 0.017 & 0.048 \\
\hline \multirow[t]{2}{*}{ 3- GDP Final } & -0.004 & 0.004 & 0.019 & 0.048 & 0.017 & 0.029 & 0.010 & 0.007 & 0.006 & 0.010 \\
\hline & \multicolumn{10}{|c|}{ Monthly Announcements } \\
\hline \multicolumn{11}{|l|}{ Real Activity } \\
\hline 4- Nonfarm Payroll Employment & $0.098 *$ & 0.189 & $0.084 *$ & 0.214 & $0.161 *$ & 0.237 & $0.144 *$ & 0.269 & $0.08^{*}$ & 0.232 \\
\hline 5- Retail Sales & $0.048^{*}$ & 0.225 & 0.019 & 0.066 & $0.067 *$ & 0.241 & $0.059 *$ & 0.170 & $0.041^{*}$ & 0.193 \\
\hline 6- Industrial Production & $0.020^{*}$ & 0.105 & $0.019^{*}$ & 0.078 & $0.029 *$ & 0.131 & $0.034 *$ & 0.147 & $0.018^{*}$ & 0.086 \\
\hline 7- Capacity Utilization & 0.017 & 0.061 & 0.016 & 0.055 & 0.021 & 0.046 & 0.023 & 0.058 & 0.018 & 0.041 \\
\hline 8- Personal Income & 0.007 & 0.015 & 0.001 & 0.000 & 0.006 & 0.007 & 0.003 & 0.001 & -0.005 & 0.005 \\
\hline 9- Consumer Credit & 0.002 & 0.002 & 0.009 & 0.019 & 0.004 & 0.012 & 0.002 & 0.002 & -0.002 & 0.004 \\
\hline \multicolumn{11}{|l|}{ Consumption } \\
\hline 10- Personal Consu & -0.003 & 0.003 & 0.005 & 0.006 & -0.007 & 0.010 & -0.011 & 0.012 & 0.007 & 0.008 \\
\hline \multicolumn{10}{|l|}{ Investment } & 0.003 \\
\hline 12- Durable Go & $0.055^{*}$ & 0.266 & $0.027 *$ & 0.081 & $0.088^{*}$ & 0.363 & $0.085^{*}$ & 0.355 & $0.043^{*}$ & 0.237 \\
\hline 13- Cons & $0.019^{*}$ & 0.087 & $0.01 *$ & 0.026 & $0.031 *$ & 0.091 & $0.017 *$ & 0.034 & 0.015 & 0.030 \\
\hline 14- Factory Orde & 0.011 & 0.024 & 0.006 & 0.006 & 0.018 & 0.038 & 0.019 & 0.041 & $0.031 *$ & 0.102 \\
\hline 15- Business Inventories & -0.004 & 0.008 & 0.01 & 0.029 & 0.009 & 0.012 & 0.002 & 0.001 & 0.007 & 0.015 \\
\hline \multicolumn{11}{|l|}{ Government Purchases } \\
\hline $\begin{array}{l}\text { 16- Government Budget Deficit } \\
\text { Net Exports }\end{array}$ & $0.007^{*}$ & 0.057 & 0.008 & 0.038 & 0.002 & 0.003 & 0.010 & 0.050 & 0.003 & 0.006 \\
\hline \multicolumn{10}{|l|}{ Prices } & 0.414 \\
\hline 18- Producer Price Index & 0.005 & 0.003 & 0.000 & 0.000 & 0.019 & 0.020 & 0.017 & 0.017 & $0.018^{*}$ & 0.046 \\
\hline \multicolumn{10}{|l|}{ Forward-Looking } & 0.027 \\
\hline 20- Consumer Confidence Index & $0.037^{*}$ & 0.174 & $0.022 *$ & 0.103 & $0.058 *$ & 0.222 & $0.054 *$ & 0.214 & $0.035^{*}$ & 0.189 \\
\hline 21- NAPM Index & $0.028^{*}$ & 0.199 & $0.012 *$ & 0.036 & $0.039 *$ & 0.141 & $0.036^{*}$ & 0.146 & $0.025^{*}$ & 0.074 \\
\hline 22- Housing Starts & 0.006 & 0.008 & 0.005 & 0.007 & 0.017 & 0.028 & $0.02 *$ & 0.033 & 0.008 & 0.009 \\
\hline \multirow[t]{2}{*}{ 23- Index of Leading Indicators } & 0.012 & 0.031 & 0.009 & 0.006 & 0.012 & 0.009 & 0.011 & 0.005 & -0.005 & 0.005 \\
\hline & \multicolumn{10}{|c|}{ Six-Week Announcements } \\
\hline \multirow[t]{2}{*}{ 24- Target Federal Funds Rate } & $0.048 *$ & 0.229 & $0.050 *$ & 0.162 & $0.072 *$ & 0.259 & $0.072 *$ & 0.230 & 0.032 & 0.142 \\
\hline & \multicolumn{10}{|c|}{ Weekly Announceme } \\
\hline 25- Initial Unemp & $-0.014 *$ & 0.025 & $-0.012 *$ & 0.019 & $-0.022 *$ & 0.036 & $-0.026^{*}$ & 0.046 & $-0.019 *$ & 0.058 \\
\hline 26- Money Supply, M1 & 0.000 & 0.000 & 0.000 & 0.000 & $0.004 *$ & 0.020 & $0.004 *$ & 0.019 & $0.002 *$ & 0.009 \\
\hline 27- Money Supply, M2 & 0.000 & 0.000 & -0.001 & 0.001 & $0.004 *$ & 0.019 & $0.005^{*}$ & 0.030 & $0.002 *$ & 0.013 \\
\hline 28- Money Supply, M3 & 0.000 & 0.000 & 0.001 & 0.002 & 0.002 & 0.004 & $0.004 *$ & 0.023 & $0.002 *$ & 0.011 \\
\hline
\end{tabular}


Table 3 (continued)

German Contemporaneous News Response Coefficients and $R^{2}$ Values

\begin{tabular}{|c|c|c|c|c|c|c|c|c|c|c|}
\hline & \multicolumn{2}{|c|}{ Pound $/ \$$} & \multicolumn{2}{|c|}{ Yen $/ \$$} & \multicolumn{2}{|c|}{$\mathrm{DM} / \$$} & \multicolumn{2}{|c|}{$\mathrm{CHF} / \$$} & \multicolumn{2}{|c|}{ Euro/\$ } \\
\hline & $\beta_{k}$ & $R^{2}$ & $\beta_{k}$ & $R^{2}$ & $\beta_{k}$ & $R^{2}$ & $\beta_{k}$ & $R^{2}$ & $\beta_{k}$ & $R^{2}$ \\
\hline \multirow{3}{*}{ 29- GDP } & & & & & terly An & iouncer & nts & & & \\
\hline & -0.004 & 0.042 & -0.002 & 0.001 & -0.007 & 0.022 & -0.011 & 0.068 & -0.004 & 0.015 \\
\hline & \multicolumn{10}{|c|}{ Monthly Announcements } \\
\hline \multicolumn{11}{|l|}{ Real Activity } \\
\hline 30- Employment & 0.000 & 0.000 & 0.002 & 0.001 & 0.000 & 0.000 & $0.01 *$ & 0.045 & 0.003 & 0.003 \\
\hline 31- Retail Sales & 0.001 & 0.001 & 0.004 & 0.008 & -0.003 & 0.004 & -0.002 & 0.003 & $-0.01 *$ & 0.091 \\
\hline $\begin{array}{l}\text { 32- Industrial Production } \\
\text { Investment }\end{array}$ & $-0.011^{*}$ & 0.059 & -0.009 & 0.036 & $-0.017 *$ & 0.172 & $-0.015^{*}$ & 0.105 & -0.005 & 0.015 \\
\hline 33- Manufacturing Orders & -0.007 & 0.025 & -0.008 & 0.029 & -0.011 & 0.061 & -0.01 & 0.042 & -0.002 & 0.002 \\
\hline 34- Manufacturing Output & -0.001 & 0.001 & $-0.017 *$ & 0.091 & -0.007 & 0.041 & -0.009 & 0.048 & -0.007 & 0.034 \\
\hline Net Exports & & & & & & & & & & \\
\hline 35- Trade Balance & -0.004 & 0.018 & 0.001 & 0.000 & 0.000 & 0.000 & 0.001 & 0.001 & -0.005 & 0.019 \\
\hline 36- Current Account & -0.003 & 0.009 & 0.006 & 0.019 & -0.006 & 0.035 & -0.006 & 0.033 & -0.006 & 0.031 \\
\hline \multicolumn{11}{|l|}{ Prices } \\
\hline 37- Consumer Price Index & $-0.020^{*}$ & 0.159 & -0.004 & 0.016 & 0.000 & 0.000 & 0.007 & 0.016 & -0.001 & 0.001 \\
\hline 38- Producer Prices & -0.002 & 0.003 & 0.003 & 0.012 & -0.003 & 0.003 & -0.004 & 0.011 & -0.008 & 0.015 \\
\hline 39- Wholesale Price Index & 0.000 & 0.000 & 0.003 & 0.003 & -0.011 & 0.039 & -0.003 & 0.005 & 0.004 & 0.012 \\
\hline 40- Import Prices & 0.007 & 0.079 & -0.009 & 0.049 & 0.003 & 0.005 & 0.006 & 0.019 & -0.003 & 0.003 \\
\hline Monetary & & & & & & & & & & \\
\hline 41- Money Stock M3 & $-0.02 *$ & 0.215 & 0.000 & 0.000 & $-0.033 *$ & 0.181 & $-0.02 *$ & 0.113 & $-0.023 *$ & 0.161 \\
\hline
\end{tabular}

Notes: We estimate the contemporaneous exchange rate news response model, $R_{t}=\beta_{k} S_{k t}+\varepsilon_{t}$, where $R_{t}$ is the 5minute return from time $t$ to time $t+1$ and $S_{k t}$ is the standardized news corresponding to announcement $k(k=1, \ldots, 41)$ made at time $t$. We estimate the regression using only those observations $\left(R_{t}, S_{k t}\right)$ such that an announcement was made at time $t$. We report the $\hat{\beta}_{k}$ and $R^{2}$ values, and we mark with an asterisk those coefficients that are statistically significant at the five percent level, using heteroskedasticity and autocorrelation consistent standard errors. 
Table 4

Return and Volatility News Response Coefficients

\begin{tabular}{|c|c|c|c|c|c|}
\hline Announcement & Pound $/ \$$ & Yen/\$ & $\mathrm{DM} / \$$ & $\mathrm{CHF} / \mathrm{\$}$ & Euro/\$ \\
\hline & \multicolumn{5}{|c|}{ Contemporaneous Return Response, $\boldsymbol{\beta}_{k 0}$} \\
\hline Nonfarm Payroll Employment & $0.092 *$ & $0.072 *$ & $0.159 *$ & $0.115^{*}$ & $0.081 *$ \\
\hline Durable Goods Orders & $0.055^{*}$ & $0.029 *$ & $0.084 *$ & $0.083 *$ & $0.041 *$ \\
\hline Trade Balance & $0.083 *$ & $0.115^{*}$ & $0.142 *$ & $0.131^{*}$ & $0.084 *$ \\
\hline \multirow[t]{2}{*}{ Initial Unemployment Claims } & $-0.010^{*}$ & $-0.009 *$ & $-0.018^{*}$ & $-0.024 *$ & $-0.017 *$ \\
\hline & \multicolumn{5}{|c|}{ Contemporaneous Volatility Response, $\beta_{k 0}$} \\
\hline Nonfarm Payroll Employment & $0.058 *$ & $0.053 *$ & $0.084 *$ & $0.077 *$ & $0.058 *$ \\
\hline Durable Goods Orders & $0.017^{*}$ & $0.010^{*}$ & $0.027^{*}$ & $0.018^{*}$ & $0.018^{*}$ \\
\hline Trade Balance & $0.023 *$ & $0.040^{*}$ & $0.034 *$ & $0.031 *$ & $0.026^{*}$ \\
\hline \multirow[t]{2}{*}{ Initial Unemployment Claims } & $0.003 *$ & $0.004 *$ & $0.010^{*}$ & $0.010^{*}$ & $0.005 *$ \\
\hline & \multicolumn{5}{|c|}{ Cumulative Volatility Response, $\sum_{j^{\prime}=0}^{J} \beta_{k j^{\prime}}$} \\
\hline Nonfarm Payroll Employment & $0.356^{*}$ & $0.328 *$ & $0.519 *$ & $0.476^{*}$ & $0.356^{*}$ \\
\hline Durable Goods Orders & $0.106^{*}$ & $0.060 *$ & $0.163^{*}$ & $0.114^{*}$ & $0.108 *$ \\
\hline Trade Balance & $0.139 *$ & $0.244^{*}$ & $0.210^{*}$ & $0.191^{*}$ & $0.161 *$ \\
\hline Initial Unemployment Claims & $0.021 *$ & $0.023 *$ & $0.059 *$ & $0.060 *$ & $0.033 *$ \\
\hline
\end{tabular}

Notes: We estimate the exchange rate conditional mean model (1), $R_{t}=\beta_{0}+\sum_{i=1}^{I} \beta_{i} R_{t-i}+\sum_{k=1}^{K} \sum_{j=0}^{J} \beta_{k j} S_{k, t-j}+\varepsilon_{t}$, and report estimates of the contemporaneous response of exchange rate returns to news, $\beta_{k 0}$. We also estimate the disturbance volatility model (2),

$$
\left|\hat{\varepsilon}_{t}\right|=c+\psi \frac{\hat{\sigma}_{d(t)}}{\sqrt{288}}+\sum_{k=1}^{K} \sum_{j^{\prime}=0}^{J^{\prime}} \beta_{k j^{\prime}}\left|S_{k, t-j^{\prime}}\right|+\left(\sum_{q=1}^{Q}\left(\delta_{q} \cos \left(\frac{q 2 \pi t}{288}\right)+\varphi_{q} \sin \left(\frac{q 2 \pi t}{288}\right)\right)+\sum_{r=1}^{R} \sum_{j^{\prime \prime}=0}^{J^{\prime \prime}} \gamma_{r j^{\prime \prime}} D_{r, t-j^{\prime \prime}}\right)+u_{t},
$$

and report estimates of the contemporaneous response of exchange rate volatility to news, $\beta_{k 0}=\gamma_{k} p_{\mathrm{k}}(0)$, as described in the text. Finally, we also report estimates of the cumulative volatility response, $\sum_{j^{\prime}=0}^{12} \gamma_{k} p_{k}\left(j^{\prime}\right)$, as described in the text. Asterisks denote statistical significance at the five percent level. 
Table 5

Return and Volatility News Response Coefficients and Announcement Dummy Coefficients

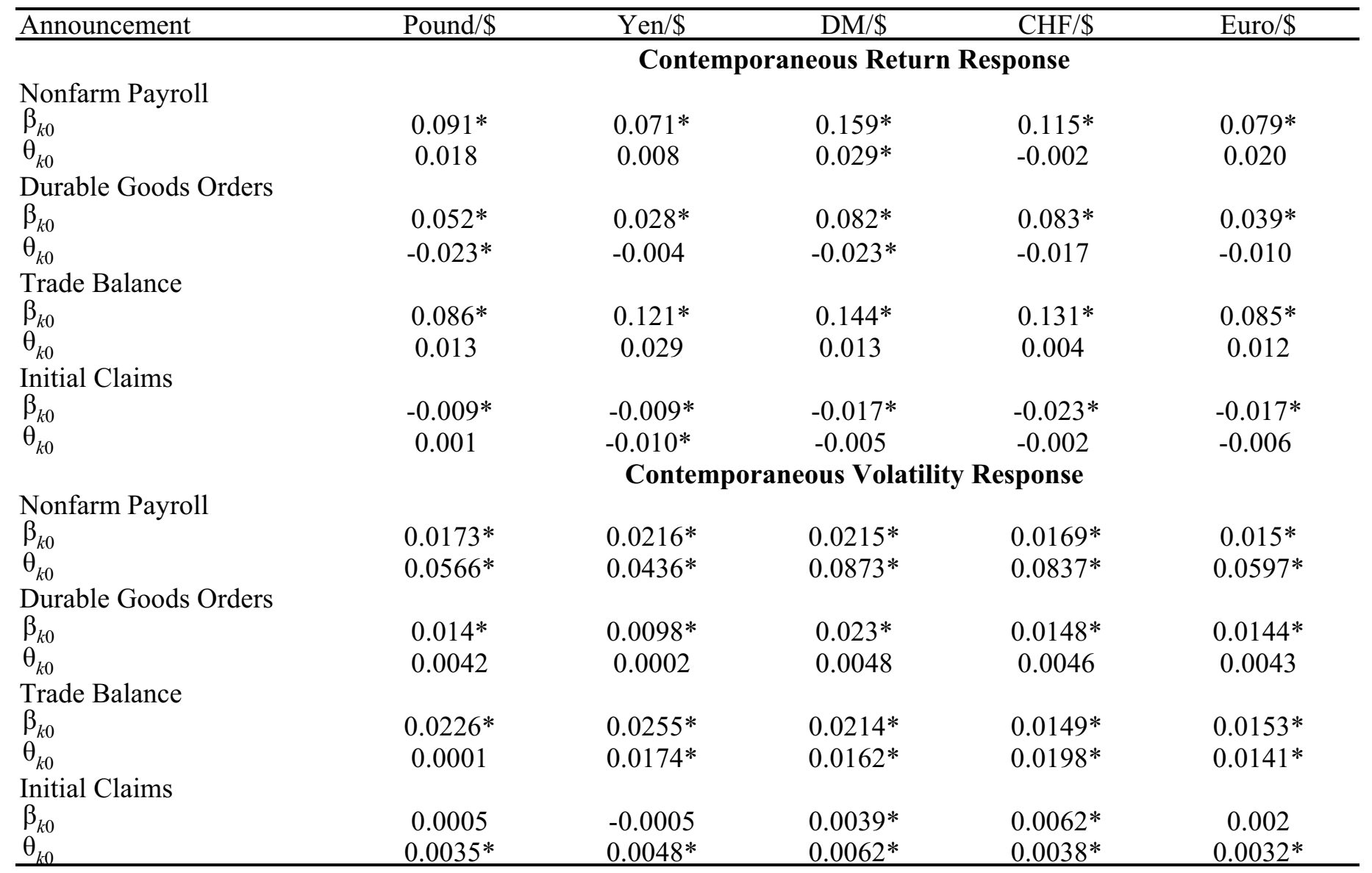

Notes: We add to equation (1) $J$ lags of announcement period dummies on each of $K$ fundamentals, $R_{t}=\beta_{0}+\sum_{i=1}^{I} \beta_{i} R_{t-i}+\sum_{k=1}^{K} \sum_{j=0}^{J} \beta_{k j} S_{k, t-j}+\sum_{k=1}^{K} \sum_{j=0}^{J} \theta_{k j} D_{k, t-j}+\varepsilon_{t} \quad$, and we report estimates of the contemporaneous return response to news and to announcement periods, $\beta_{k 0}$ and $\theta_{k 0}$, respectively. We also add to equation (2) $J$ ' lags of announcement period dummies on each of $K$ fundamentals, $\left|\hat{\varepsilon}_{t}\right|=c+\psi \frac{\hat{\sigma}_{d(t)}}{\sqrt{288}}+\sum_{k=1}^{K} \sum_{j^{\prime}=0}^{J^{\prime}} \beta_{k j^{\prime}}\left|S_{k, t-j^{\prime}}\right|+\sum_{k=1}^{K} \sum_{j^{\prime}=0}^{J^{\prime}} \theta_{k j^{\prime}} D_{k, t-j^{\prime}}+\left(\sum_{q=1}^{Q}\left(\delta_{q} \cos \left(\frac{q 2 \pi t}{288}\right)+\varphi_{q} \sin \left(\frac{q 2 \pi t}{288}\right)\right)+\sum_{r=1}^{R} \sum_{j^{\prime \prime}=0}^{J^{\prime \prime}} \gamma_{r j^{\prime \prime}} D_{r, t-j^{\prime \prime}}\right)+u_{t}$, and report estimates of the contemporaneous return response to news and to announcement periods, $\beta_{k 0}$ and $\theta_{k 0}$, respectively. Asterisks denote statistical significance at the five percent level. 
Figure 1

Sample Autocorrelation Functions

Returns and Absolute Returns

Pound/\$ Returns

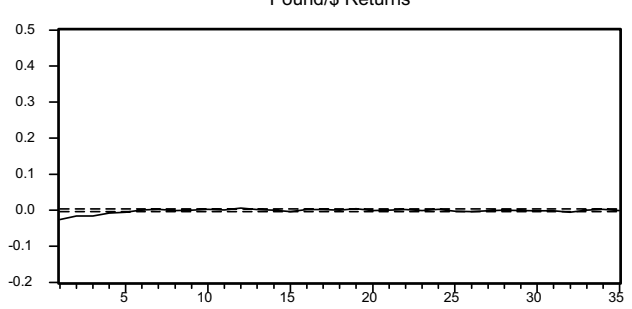

Yen/\$ Returns

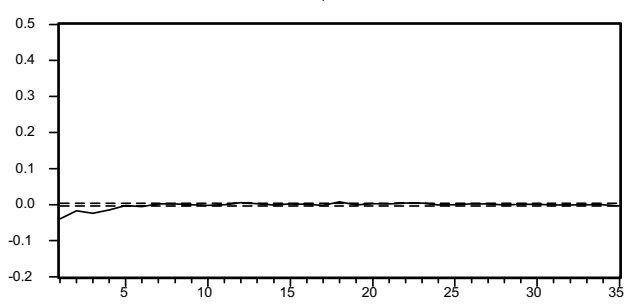

DM/\$ Returns

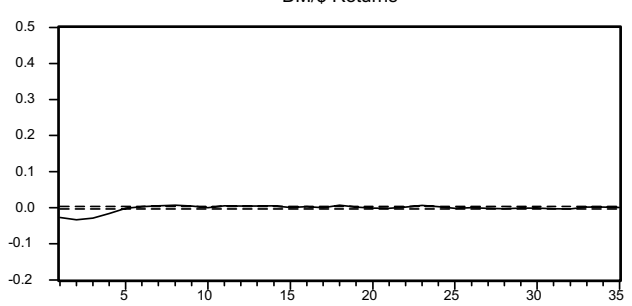

$\mathrm{CHF} / \$$ Returns

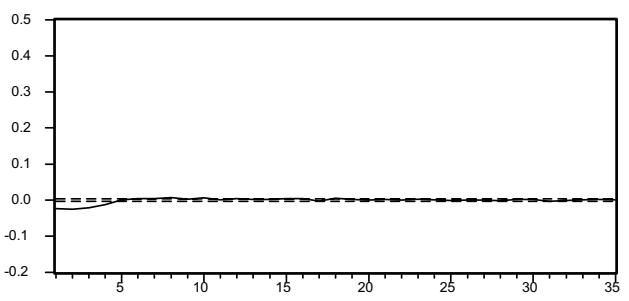

Euro/\$ Returns

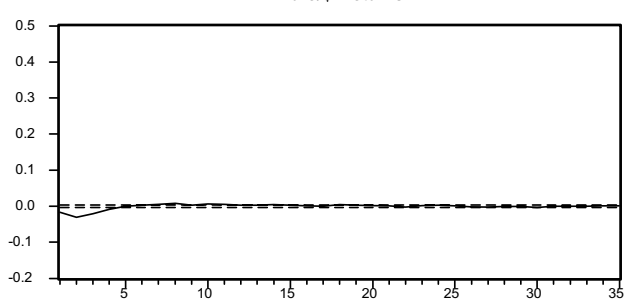

Pound/\$ Absolute Returns

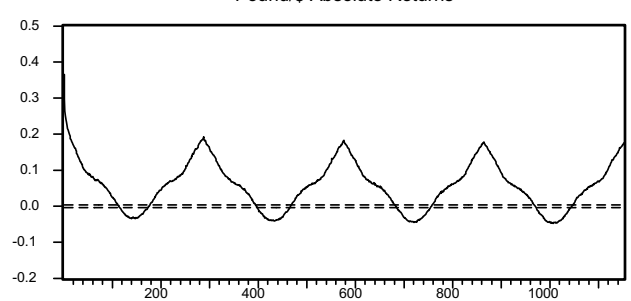

Yen/\$ Absolute Returns

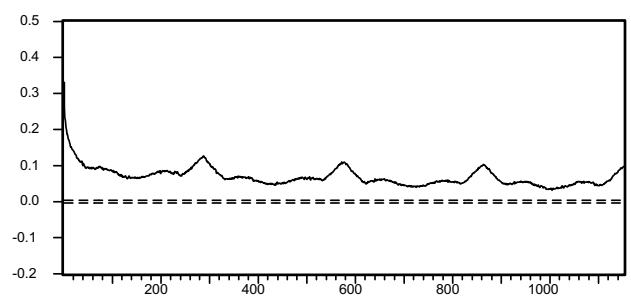

DM/\$ Absolute Returns

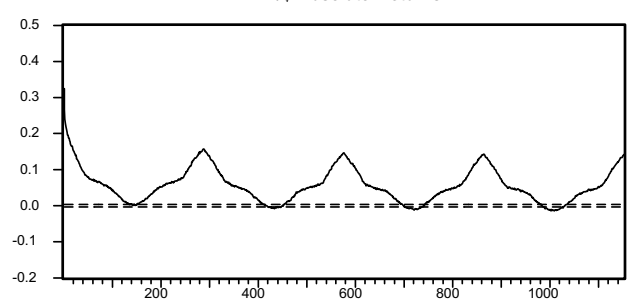

$\mathrm{CHF} / \$$ Absolute Returns

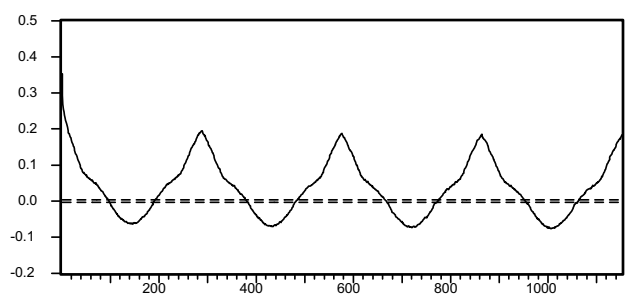

Euro/\$ Absolute Returns

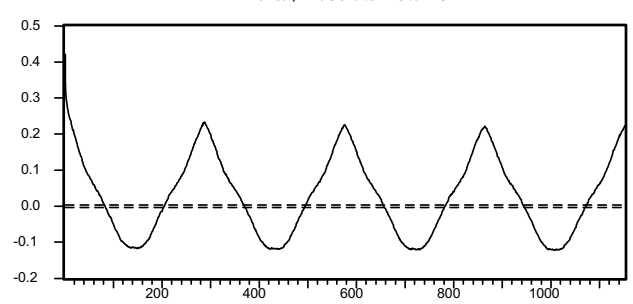

Notes: We plot the sample autocorrelations of returns and absolute returns for five currencies, together with Bartlett's approximate ninety-five percent confidence bands under the null hypothesis of white noise. In each graph, the vertical axis is the sample autocorrelation and the horizontal axis is displacement in 5-minute intervals. To avoid contamination from shifts in and out of daylight savings time, we calculate the sample autocorrelations using only days corresponding to U.S. daylight savings time. 
Figure 2

Actual and Fitted Intraday Volatility Patterns
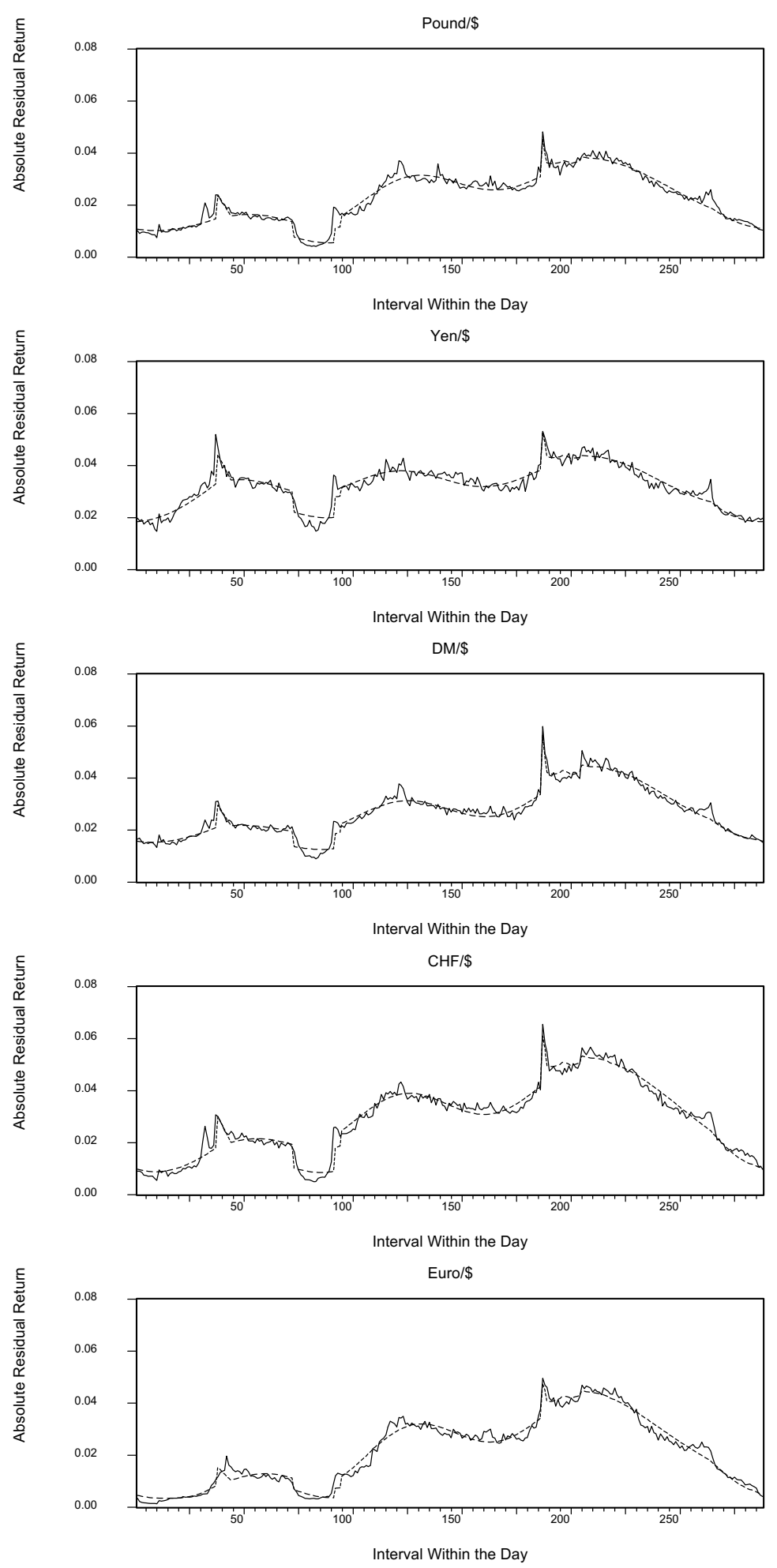

Notes: The solid line is the average intraday pattern of the absolute residual return $\left|\hat{\varepsilon}_{t}\right|$ over the 288 5-minute intervals within the day, where $\hat{\varepsilon}_{t}$ is the residual from the exchange rate conditional mean model (1) in the text. The dashed line is the fitted intraday pattern of $\left|\hat{\varepsilon}_{t}\right|$ from the exchange rate volatility model (2) in the text. To avoid contamination from shifts in and out of daylight savings time, we construct the figures using only days corresponding to U.S. daylight savings time. 
Figure 3

Exchange Rate Responses to U.S. News
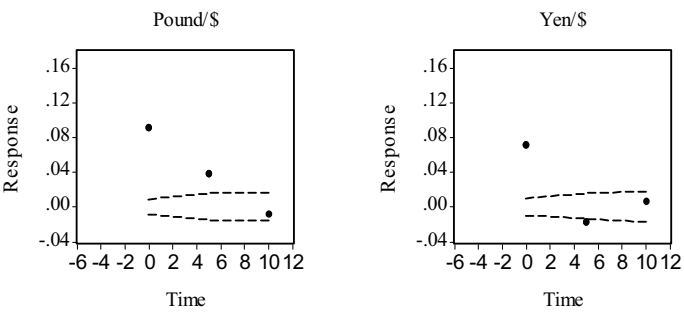

\section{Payroll Employment}
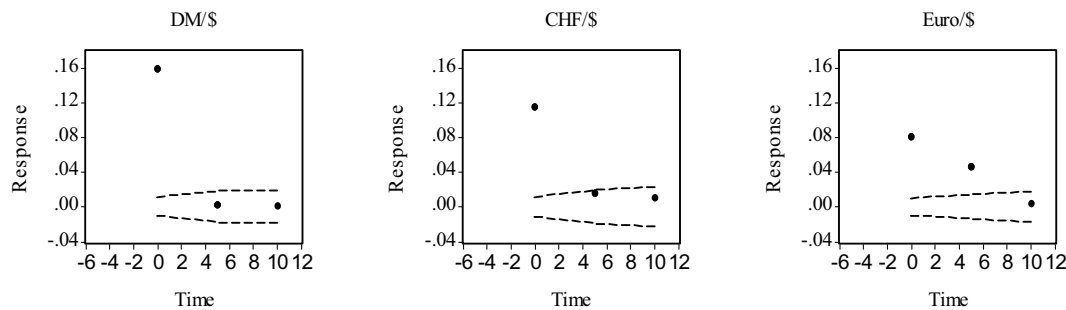

\section{Durable Goods Orders}
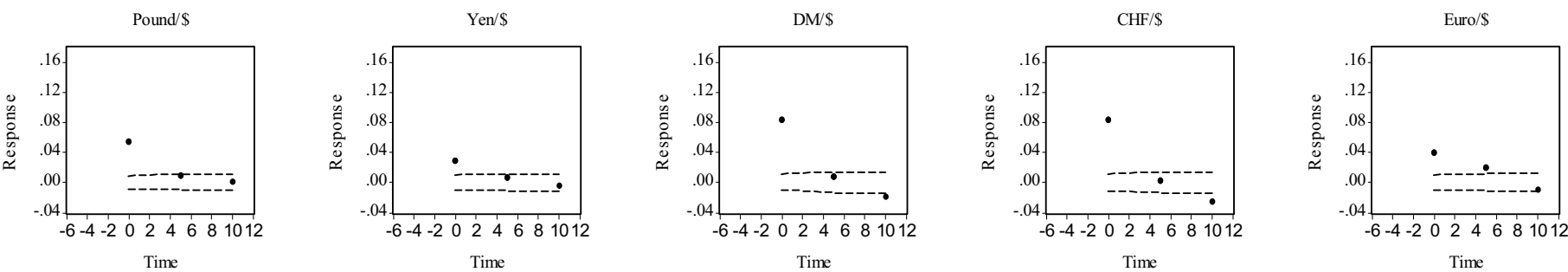

Trade Balance
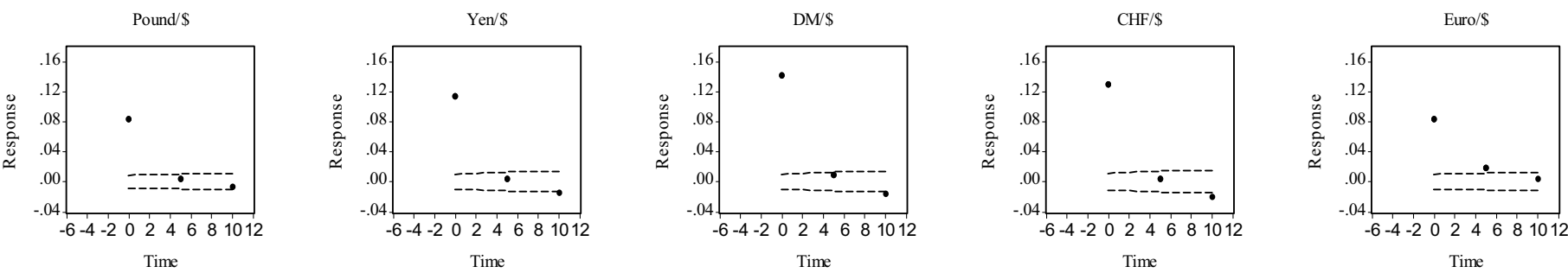

Initial Claims
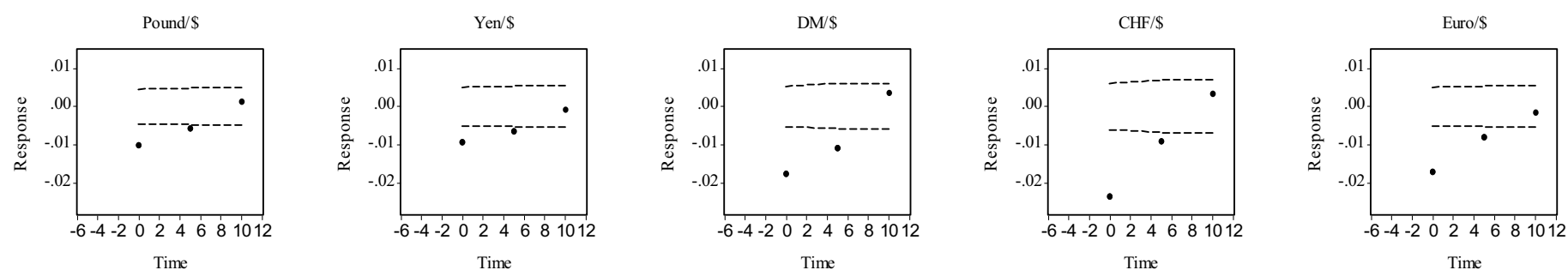

Notes: We graph the three news response coefficients associated with the exchange rate conditional mean regression (1), corresponding to responses at the announcement, five minutes after the announcement, and ten minutes after the announcement. We also show two standard error bands, under the null hypothesis of a zero response, obtained using the weighted least squares estimation method described in the text. 
Figure 4

U.S. News Effects as a Function of Release Time
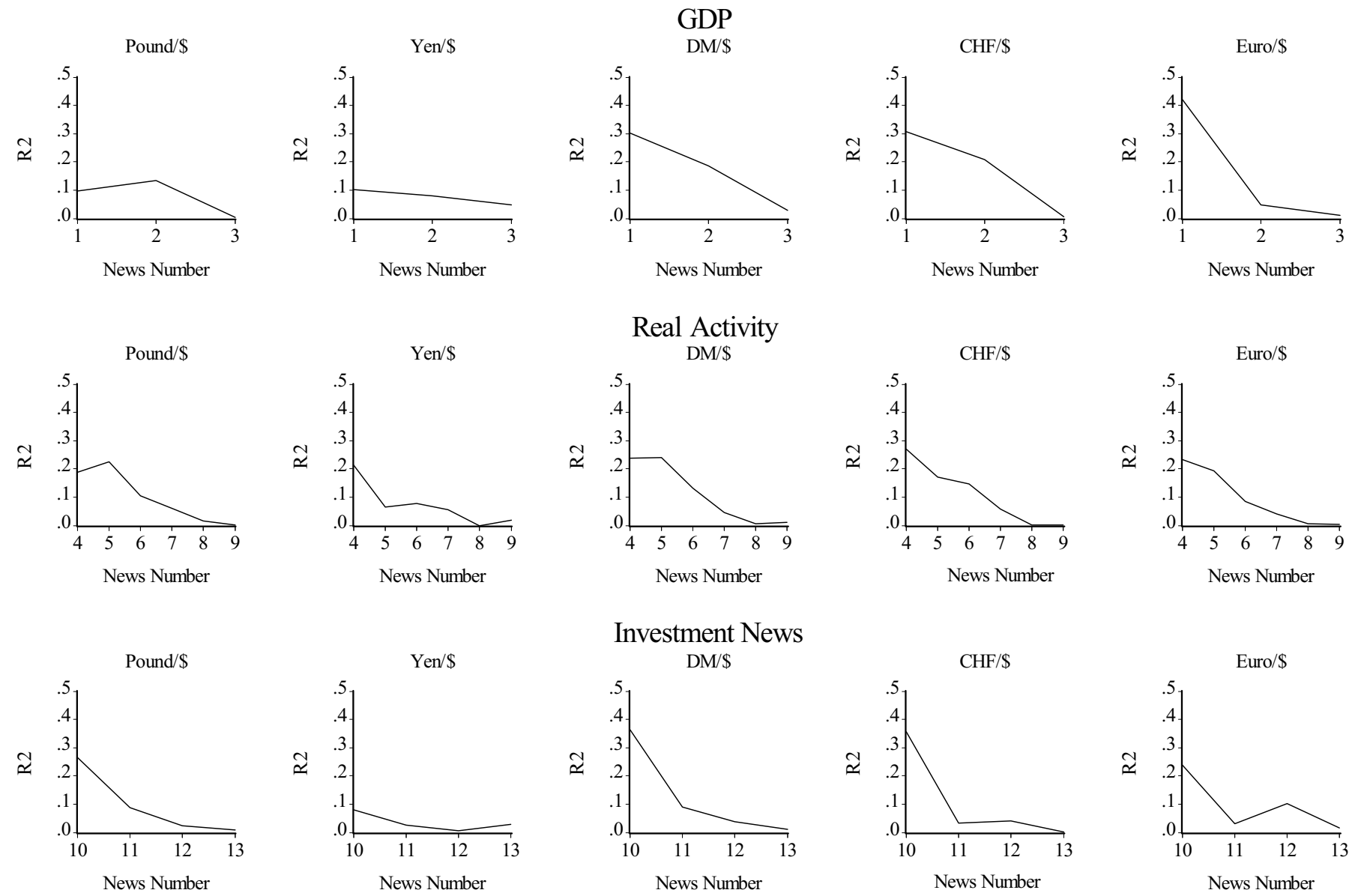

\section{Investment News}
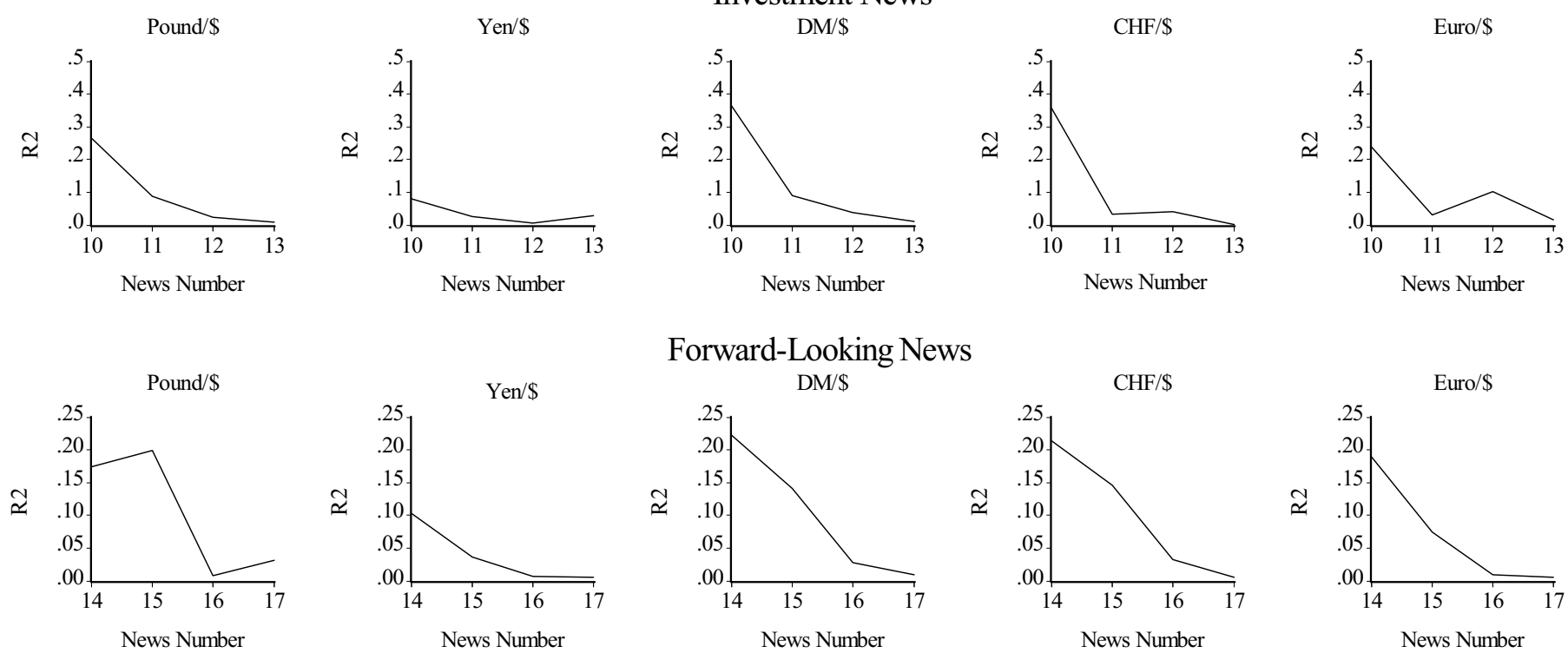

\section{Forward-Looking News}
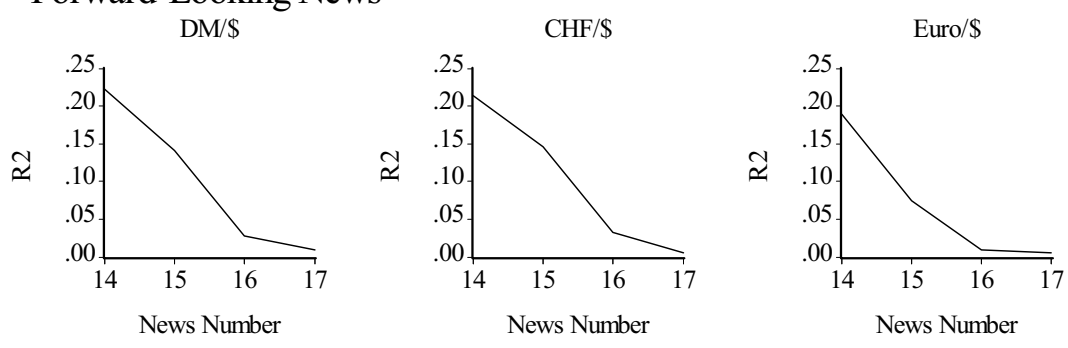

Notes: We estimate the contemporaneous exchange rate news response model, $R_{t}=\beta_{k} S_{k t}+\varepsilon_{t}$, where $R_{t}$ is the 5minute return from time $t$ to time $t+1$ and $S_{k t}$ is the standardized news corresponding to announcement $k(k=1, \ldots, 17)$ made at time $t$. We estimate the regression using only those observations $\left(R_{t}, S_{k t}\right)$ such that an announcement was made at time $t$. On the vertical axis we display the $R^{2}$ values, and on the horizontal axis we display macroeconomic news announcements in the chronological order documented in Table 2. The "news numbers" are as follows:

\section{GDP}

1- GDP Advance

2- GDP Preliminary

3- GDP Final
Real Activity

4- Payroll Employment

5- Retail Sales

6- Industrial Production

7- Capacity Utilization

8- Personal Income

9- Consumer Credit
Investment

10- Durable Goods Orders

11- Construction Spending

12- Factory Orders

13- Business Inventories
Forward-Looking

14- Consumer Confidence

15- NAPM Index

16- Housing Starts

17- Index of Leading Indicators 
Figure 5

U.S. News Impact Curves
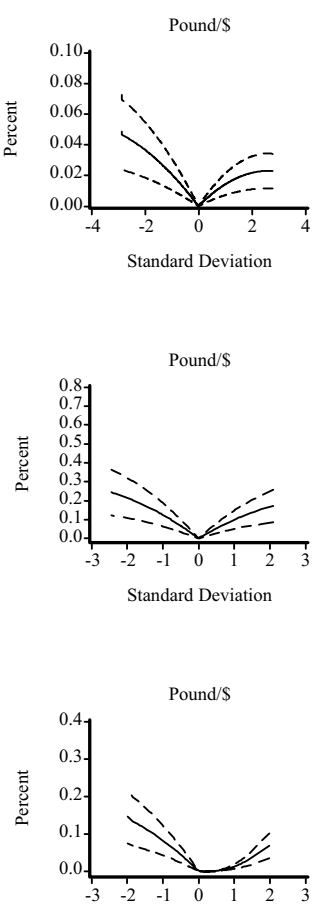

Standard Deviation

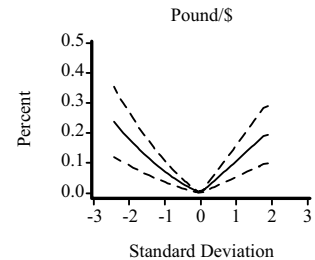

Pound/\$

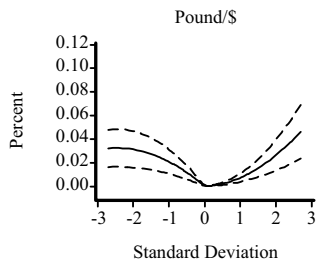

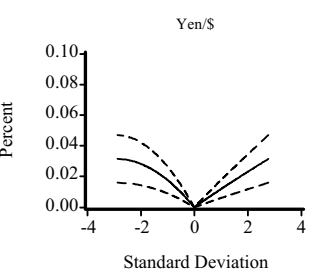

Yen/\$
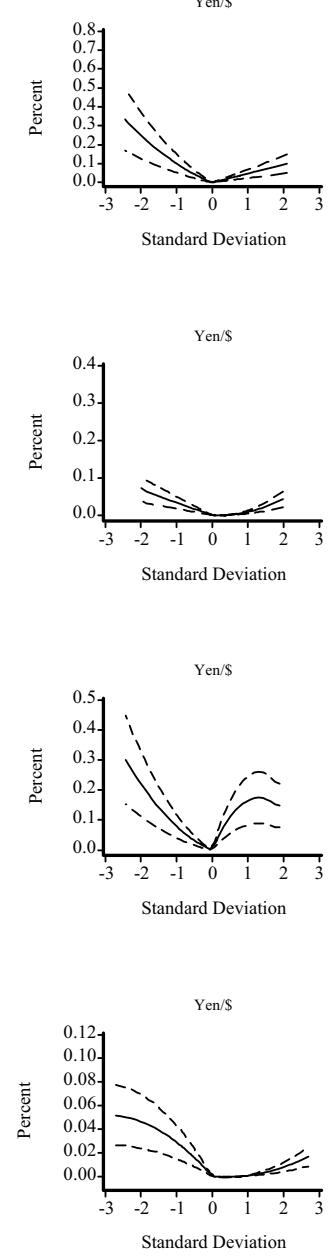

Average Over Forty Indicators
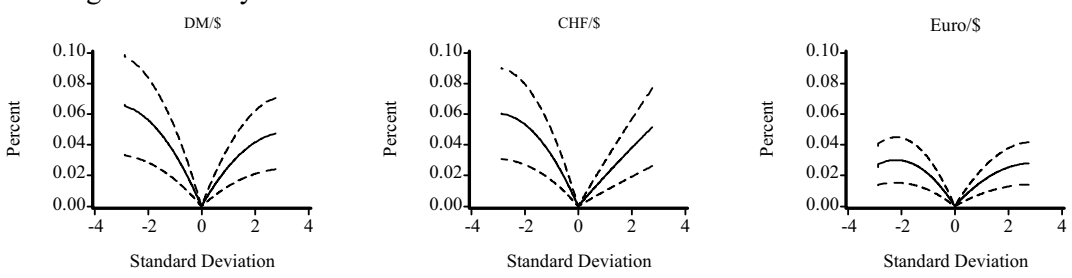

Payroll Employment
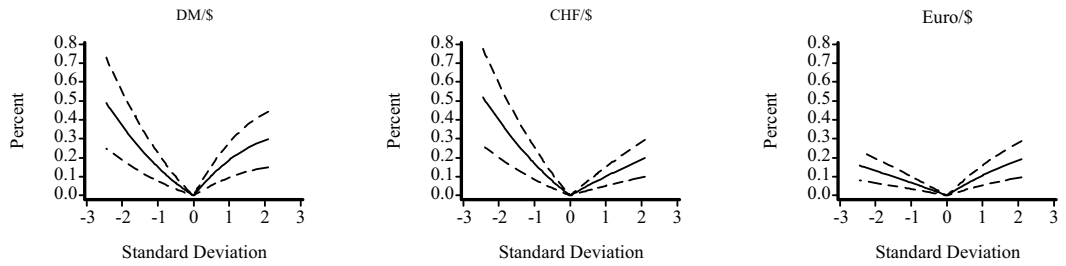

Durable Goods Orders
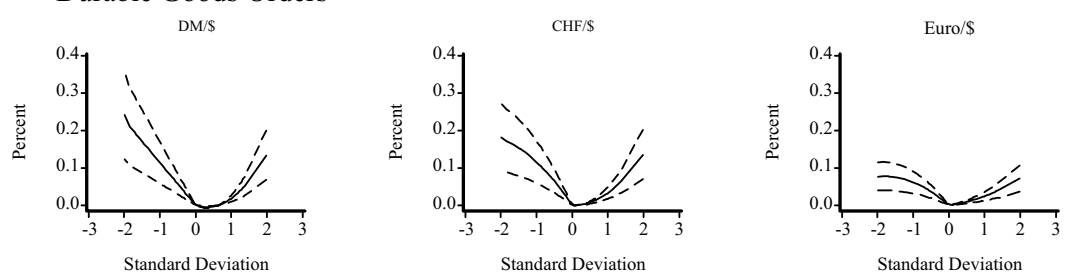

Trade Balance
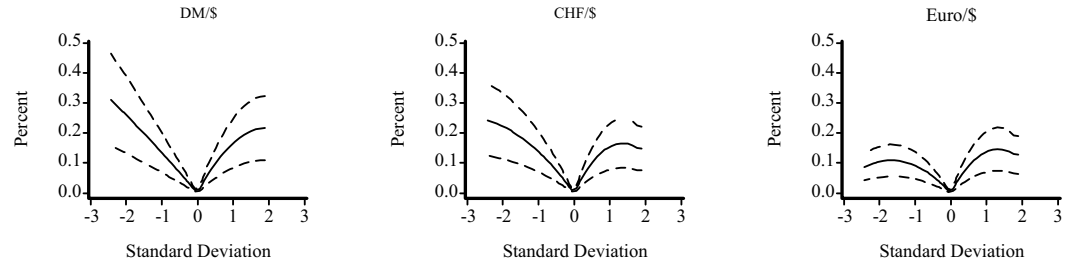

Initial Claims
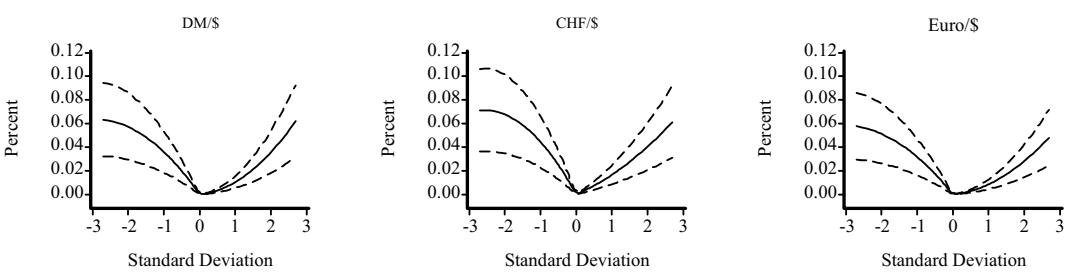

Notes: In the top row we show the news impact curves averaged across all macroeconomic fundamentals, $k=1, \ldots, 41$. In the remaining rows we show the news impact curves for payroll employment, trade balance, durable good orders and initial claims. See text for details. 
Figure 6

Forecast Uncertainty
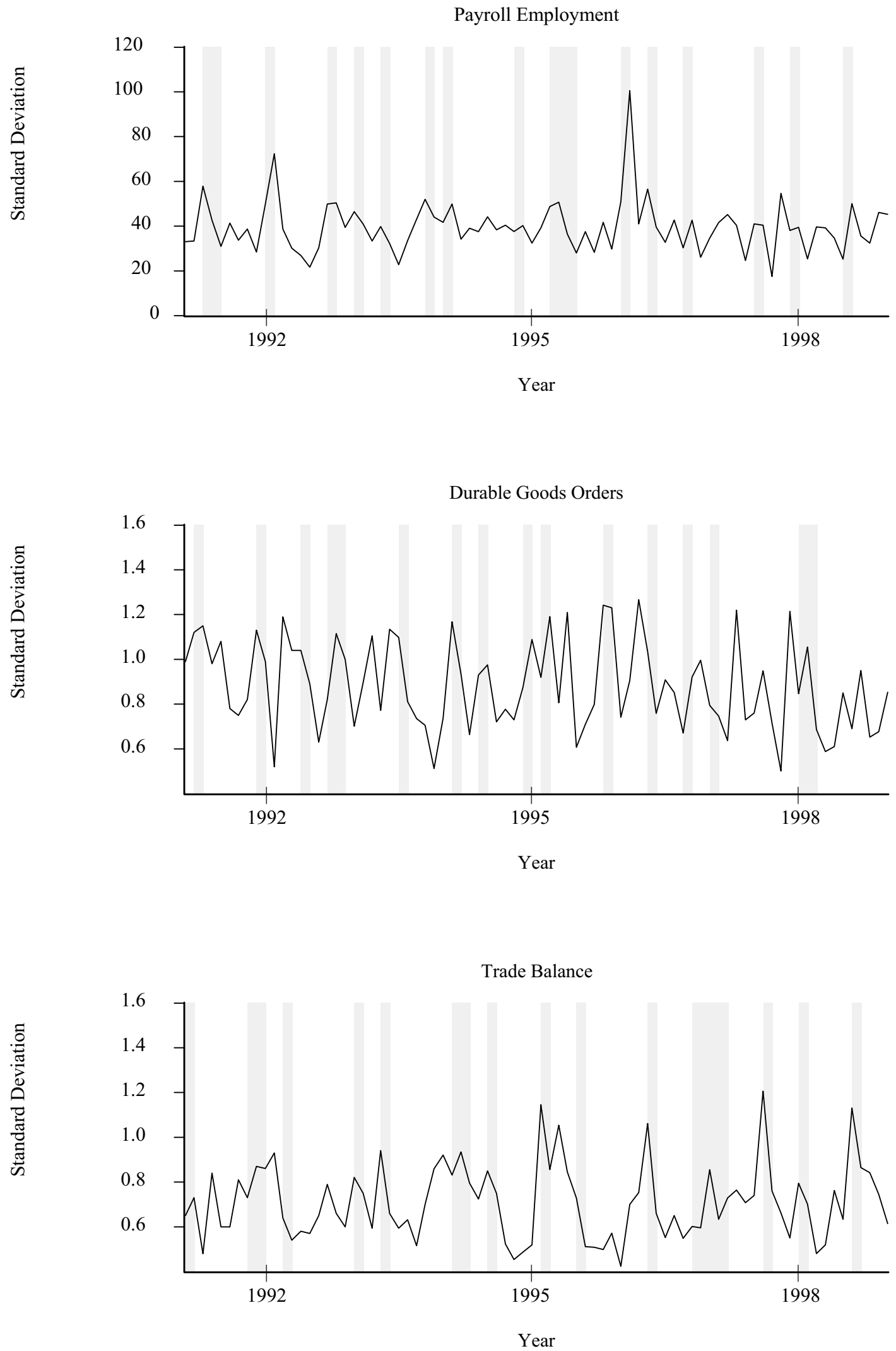

Notes: We plot the time series of cross-sectional standard deviations of the Money Market Services forecasts. The shaded areas denote "bad news" times. See text for details. 